\title{
WORLD
}

RES OURCES

WORKING PAPER

\author{
IN ST ITUTE
}

\section{LOCAL GOVERNMENT VOICES IN WHOLESALE MARKET ISSUES: ENGAGEMENT APPROACHES FOR DECARBONIZATION}

\section{EXECUTIVE SUMMARY}

\section{Highlights}

This working paper provides local governments (such as cities and counties) with clean energy goals, education on why and how they may want to engage in issues at the wholesale market-level, and examples of how other similar stakeholders are already working in this area.

- Organized wholesale markets in the United States enable renewable energy purchasing and integration; however, barriers to clean energy that undermine the goals of local governments can arise in market rules, interaction with state policies, or planning functions.

- As large energy purchasers and public institutions, local governments have a stake in the structure and administration of these markets and could play a unique role in addressing these issues.

- There are multiple potential avenues for local governments to engage at the wholesale market level, but participation has been limited due to barriers such as lack of staff capacity, high education needs, significant time commitment, and other costs.

Local governments have opportunities to comment publicly on issues, engage in proceedings or events at the level of the Federal Energy Regulatory Commission (FERC), participate in the stakeholder processes of regional transmission organizations (RTOs), communicate directly with their RTO staff, and work in collaboration with others.

\section{CONTENTS}

Executive Summary ..................................

Introduction ....................................... 2

1. Local Government Clean Energy Goals

and Organized Wholesale Markets .................... 5

2. Wholesale Market Engagement Pathways ..........11

3. Relevant Stakeholders Engaging

in Organized Wholesale Markets......................23

Conclusion......................................... 29

Appendix A ..................................... 31

Appendix B ..................................... 32

Endnotes............................................ 36

References ..................................... 37

Acknowledgments............................... 39

Working Papers contain preliminary research, analysis, findings, and recommendations. They are circulated to stimulate timely discussion and critical feedback, and to influence ongoing debate on emerging issues. Working papers may eventually be published in another form and their content may be revised.

Suggested Citation: Ratz, H.B., P. Roche, and N. Hutchinson. 2021. "Local Government Voices in Wholesale Market Issues: Engagement Approaches for Decarbonization" Working Paper. Washington, DC: World Resources Institute. Available online at doi.org/10.46830/wriwp.19.00052. 
By surveying how other similar stakeholders engage

along these pathways, local governments can

learn from those examples, understand how they

fit into dialogues already underway, and identify

potential partners.

Local governments within the territory of PJM (an abbreviation that originally stood for Pennsylvania, New Jersey, and Maryland, though the group now also includes other states and parts of states) have organized into a coalition to engage with their RTO and overcome engagement barriers.

\section{INTRODUCTION}

Local governments with ambitious goals to power municipal operations or communities with renewable energy and drive regional decarbonization can engage in wholesale market-level issues to encourage removal of clean energy barriers. Examples of issues and barriers to clean energy are described in Section 1 of this paper. Section 2 describes the types of actions local governments may pursue when engaging on these issues (Figure ES-1 also gives examples of engagement actions). In areas of the United States where regional transmission operators or independent system operators (RTOs/ISOs) manage organized wholesale markets, the rules and planning functions designed by these entities can impact both clean energy purchases and the pace of decarbonization. While local governments have not been an active voice in dialogues that address wholesale-level issues in the past, they are increasingly interested in engaging due to the potential impact on their goals. Local governments are unique stakeholders within wholesale power markets as both large energy purchasers and public institutions that represent consumers and provide clean energy leadership. To assist local governments as they begin to assess the potential value of engagement, this paper explains why they may want to engage, the pathways that exist and some considerations for pursuing them, and examples of other relevant stakeholders' engagement.

\section{The Opportunity}

Wholesale market dialogues present a new level of opportunity for local governments to weigh in on clean energy and decarbonization barriers affecting a multistate region. Currently, local governments working to resolve problems related to clean energy generation and transmission development engage with their utility, its regulator (often the state public utility commission), or at the state legislature. In areas where competitive, organized wholesale markets have evolved, the RTOs managing these multistate markets and their regulator (the Federal Energy Regulatory Commission, or FERC) are additional avenues for local governments to engage. Local governments should be aware also that the regulatory construct in each area shapes the roles of different parties and thus the opportunity. ${ }^{1}$ While some local governments may have experience engaging at the state level, either legislatively with state regulators or directly with their utilities, fewer have experience working with RTOs or FERC (see ACCC 2020).

Where wholesale market barriers limit renewable energy development or undermine broad decarbonization efforts, the lack of a local government voice is a significant missed opportunity. While organized wholesale markets increase customer options for purchasing renewable energy and improve renewable energy integration into the grid, barriers to clean energy can arise when markets have not yet evolved alongside new clean energy technologies. Wholesale markets were not designed to incorporate technologies such as energy storage or solar-plus-storage. Barriers arise in market rules or operating procedures when they are not updated to fully allow these resources to compete against others. Barriers can also arise within planning processes that need to be updated. In some markets, insufficient transmission planning limits the ability to connect new renewable energy projects and meet demand for these resources. Finally, some RTOs have found state clean energy policies to be incompatible with current wholesale market frameworks and have sought to minimize state support for these resources. Local governments require a basic understanding of how these clean energy barriers arise in order to decide whether or not to become involved, and how to participate most effectively in decision-making processes. As local governments gain a fuller understanding of wholesale markets, they could support broader reforms related to market design.

There are several pathways for local governments to become involved in the development of wholesale market rules and practices: through public statements, action at the FERC level, and action at the RTO level. Figure ES-1 highlights these pathways and major actions that could flow from each. These pathways are not mutually exclusive and can best be thought of as a menu of options local governments should understand if they choose to develop an engagement strategy. To fully take advantage of these pathways, local govern- 
ments will need to understand the relationship between FERC and the RTOs it regulates. They also will require education on RTO membership, stakeholder processes, and governance structures.

For each pathway, local governments will need to assess the relative effort and potential value specific to their market, the issues at hand, and their goals. In many cases, partnering or building coalitions with others can reduce the effort and maximize the impact of engagement. Some actions local governments could pursue are more formal, time-consuming, or expensive, such as participating in FERC proceedings or becoming an official RTO member with voting rights. Other actions, such as participation in events, participating as a nonvoting member in stakeholder outreach, direct engagement with RTO staff, or public statements made outside of the regulatory process, may be easier to accomplish but may not have as direct an impact on issues at hand. Many of these pathways and actions can be pursued in partnership with other stakeholders or in coalitions to overcome barriers related to staff capacity or expertise.

\section{About This Paper}

This paper educates local governments broadly on how they may want to engage in wholesale market-level issues that impact clean energy and the pathways to do so. It also provides key examples of other stakeholders already working on these issues. We begin Section 1 by providing local governments with a high-level introduction to how their clean energy goals and renewable energy purchases are impacted by issues at the wholesale market level. The majority of this paper, Section 2, then proposes potential pathways for local governments to weigh in on these issues. We focus on explaining the pathways and introducing considerations that local governments would assess in developing their own engagement strategy. The descrip-

Figure ES-1 | Engagement Pathways for Local Governments

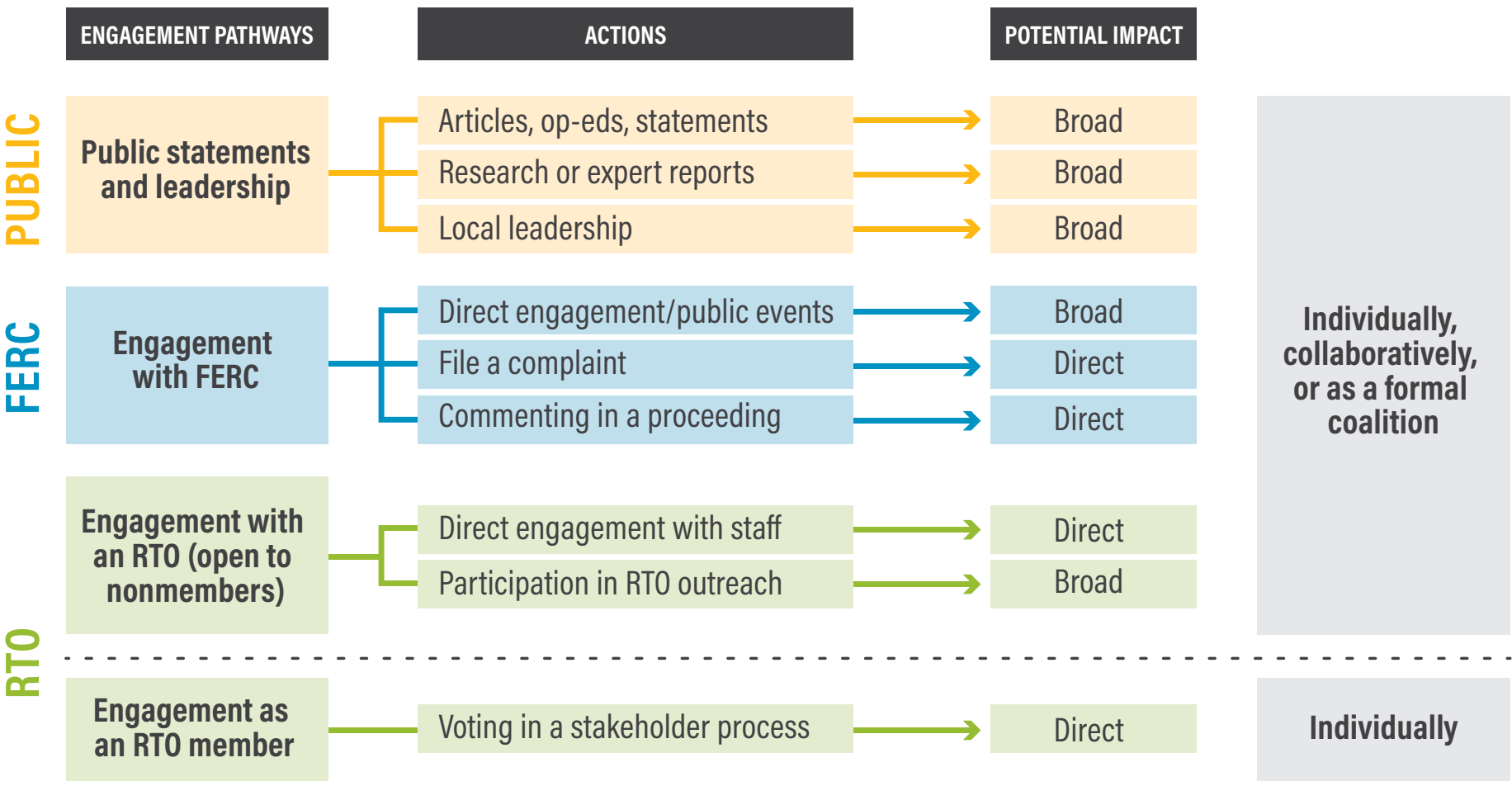


tion of these pathways includes relevant background information local governments may need to understand the roles that FERC and RTOs play and how they engage with various stakeholders. The paper concludes with examples of how states, consumer advocates, environmental groups, corporates, and local governments have engaged along these pathways. Other relevant stakeholders' experiences, described in Section 3, can help local governments better understand the pathways, and the landscape of parties engaging with RTOs.

While this paper contributes useful education and the "why," "how," and "who" related to wholesale market engagement, it is not intended to fully explain the barriers that currently exist across all of the RTOs; instead, we offer it as a starting point for local governments considering their engagement strategies. Local governments may choose to first identify the specific barriers in their markets, as well as their goals, local context, capacity, and expertise. For each pathway and action, considering the time commitment required, any costs, and the relative impact of their engagement is an important step to maximize their efforts. Local governments working to understand how their voice provides unique input into these market issues, compared to others, can consider this as the "who" if they decide to work with similarly aligned stakeholders to enter these dialogues.

\section{Methodology}

Much of the information covered in this paper was collected through WRI's engagement with the newly formed PJM Cities and Communities Coalition (PJMCCC) in 2019-21. During this time, WRI assisted the nascent coalition with research support that included coalition-building best practices, education on PJM's governance structure, and a landscape review of other organization types engaging with PJM on clean energy issues. WRI has also played a role in facilitating work across member cities to identify policy priorities and engage on wholesale market issues in the PJM region. This experience provided insight into the challenges engagement poses for cities with clean energy goals, as well as the benefits it offers them. In the first year of the project, WRI also worked closely with a team from Enel X that acted as a PJM subject matter expert. Enel X provided insight into PJM issues affecting clean energy development, relevant working groups active within PJM, and considerations for local governments interested in formal PJM membership with voting rights. For this reason, many of the examples highlighted in the paper are focused on the PJM territory, although additional research was conducted for this paper to identify examples and details from other markets.

Recognizing that for many local governments this is a new area of engagement and few resources exist that specifically address what pathways exist for local governments, WRI worked with PJMCCC members to capture their input and perspective stemming from their experiences. In addition, an advisory committee of experts on wholesale markets, RTO governance, and corporate wholesale market engagement was assembled to review new research. The advisory group also included local governments in different markets to help identify information that could be most useful to local governments considering engagement. A full list of these advisors is included in the Acknowledgments.

\section{Conclusions}

\section{As local governments work toward achieving their renewable and clean energy goals, expand- ing their regulatory engagement to include issues at the wholesale market level could help remove barriers to their own purchases as well as drive regional clean energy development. Wholesale markets are a key tool for increasing renewable energy purchasing and integration, but they are also evolving to meet the industry's changing needs.}

Local governments have several pathways to engage in wholesale market issues and may be interested in doing so to remove barriers that threaten their clean energy goals and regional decarbonization. Local governments can begin by understanding why they might engage and the pathways to engage. They can also become familiar with how other relevant stakeholders in their market are already contributing in order to develop partnerships with other stakeholders that have similar interests or, at a minimum, understand how their efforts could complement the work of others.

The pathways covered by this paper-public comment, FERC engagement, and RTO engagement-are not mutually exclusive, and several highlighted potential actions are related to each. Local governments may develop strategies that use a blend of approaches, depending on the engagement opportunities available in their specific RTO.

By undertaking pathways or actions in regional coalitions, local governments can help overcome barriers related to 
capacity, time, and expertise. The emergence of PJMCCC is a key example of this interest in engagement and the unique voice cities can contribute to dialogues on issues at the wholesale market level. Other local governments learning from PJMCCC's experiences may see opportunity in their own markets to share their voice on wholesale market-level issues impacting clean energy and drive meaningful change.

\section{LOCAL GOVERNMENT CLEAN ENERGY GOALS AND ORGANIZED WHOLESALE MARKETS}

\subsection{The Importance of Organized Wholesale Markets to Local Governments with Clean Energy Goals}

The last five years have seen rapid growth in the number of U.S. local governments setting and beginning to work toward ambitious clean energy goals. Cities represent over 50 percent of the emissions in the United States, and the recent report by the Intergovernmental Panel on Climate Change on limiting global warming to 1.5 degrees has been a key driver to accelerate decarbonization efforts in the power sector. As of 2020, over 130 local governments have clean energy goals that will be achieved through renewable energy purchases (America's Pledge 2020). Local governments are unique in that they set renewable energy goals related to their own municipal energy use as well as community-wide goals that include residential and commercial usage. Many local governments also have complementary goals related to greenhouse gas reductions, air quality, distributed energy resources (DERs), energy efficiency, electrification, and other clean energy solutions.

Local governments are increasingly interested in expanding their engagement with utilities and regulators, recognizing that decisions made at the utility and state levels can impact their ability to meet their clean energy goals as well as clean energy development across the broader grid. This interest has recently expanded to also include engagement with regional transmission organizations or independent system operators (RTOs/ISOs) ${ }^{2}$ at the regional wholesale market level because of these grid operators' role in designing and managing markets that impact clean energy development. Not all local governments are located in organized wholesale markets, but two-thirds of U.S. electricity consumers live in regions with such markets (see Figure 1).
Organized markets are known to provide many benefits that enable renewable energy development, such as providing access to renewables and integrating them into the grid more efficiently, but they can also pose barriers to decarbonization. RTOs' market rules and planning functions, and the market's interaction with state policies, can impact clean energy development either positively or negatively. Understanding and engaging in these markets is becoming increasingly important for local governments working to increase their renewable and clean energy ambitions.

\subsection{Organized Wholesale Markets as Enablers of Renewable Energy Development}

Over 80 percent of solar and wind capacity in the United States has been developed in areas managed by RTOs (NREL 2018), in part because of the important benefits they provide in terms of market access, price transparency, efficiency, and renewable integration. Well-organized wholesale markets are increasingly viewed as an important tool in regional decarbonization (Ballentine 2020; AEE 2021). Decisions made at the organized wholesale market level can impact the cost for and ability of local governments to procure affordable renewables at scale.

Organized wholesale markets expand access to renewable energy by allowing a wider set of entities to sell or purchase power from the grid. Competition and transparent market prices support developer investment in renewable energy in these markets. These benefits are notable, as organized wholesale markets combined with retail choice provide local governments and other customers with the most options for accessing renewable energy and a wider range of projects to choose from. (See Appendix A for more detail on how local governments procure renewable energy.) While many local governments purchase renewable energy through physical power purchase agreements (PPAs) with developers within their local wholesale market, organized markets provide some level of access to renewable investment regardless of their location and regulatory environment. Local governments in non-RTO areas can still drive renewable energy investment by entering into virtual PPAs in organized markets in which they are not located. ${ }^{3}$ Transaction data on local government procurement of renewable energy highlight a concentration of local government renewable purchases in four organized wholesale markets: the California ISO (CAISO), the Electric Reliability Council of Texas (ERCOT), PJM (an abbreviation that originally stood for Pennsylvania, 


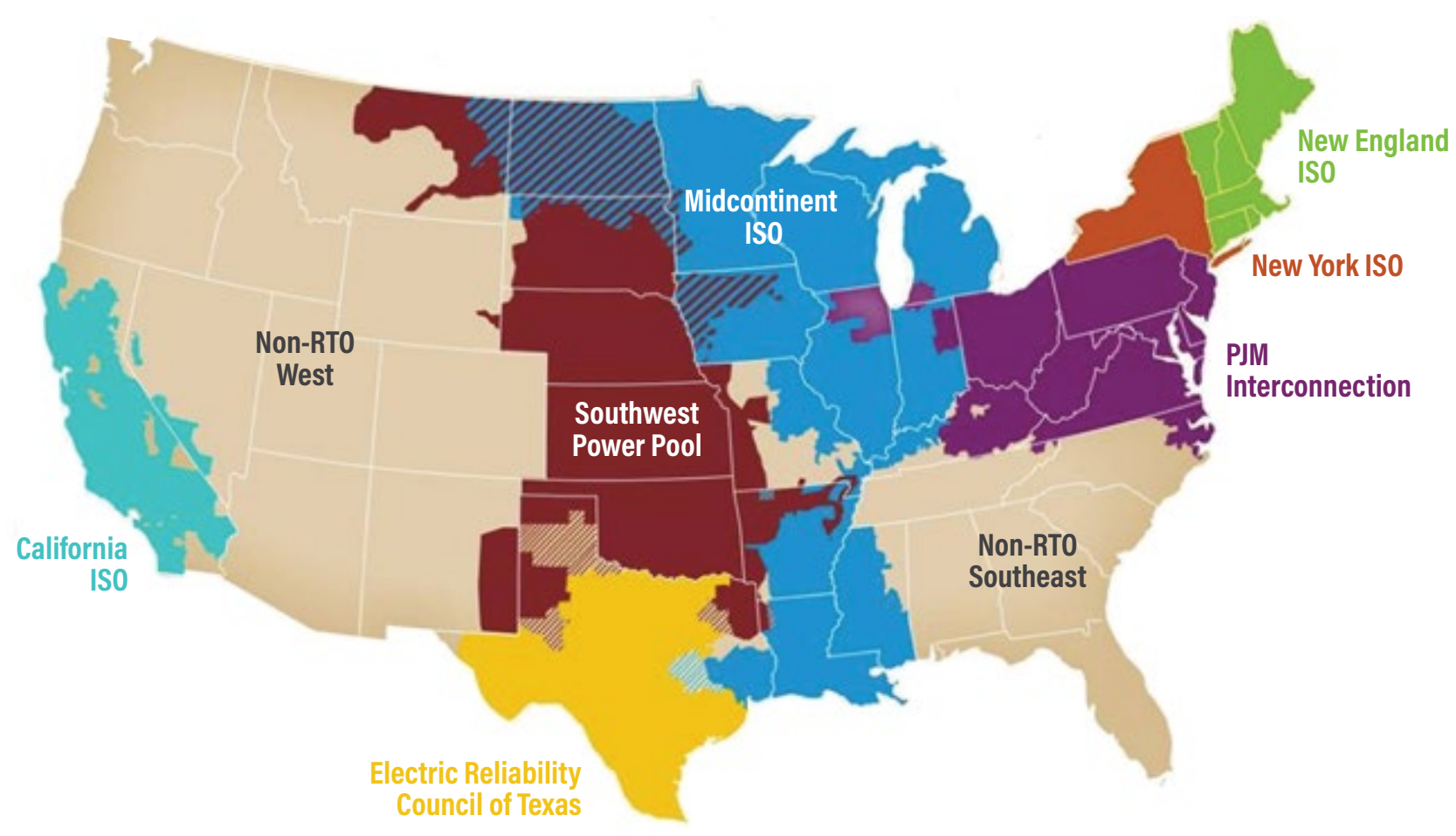

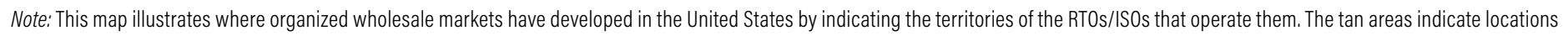

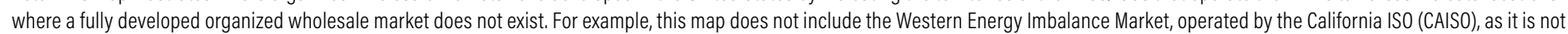

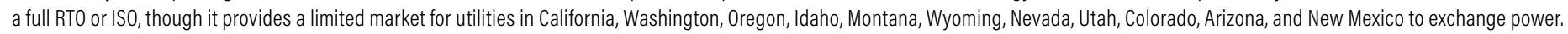

California ISO (CAISO), Southwest Power Pool (SPP), Electric Reliability Council of Texas (ERCOT), Midcontinent ISO (MISO), New York ISO (NYISO)

Source: Adapted from FERC (2021).

New Jersey, and Maryland but now includes other states and parts of other states as well, as shown in Figure 1), and the Midcontinent ISO (MISO) (Gonçalves and Liu 2020). Corporate purchases for renewable energy are also concentrated in organized wholesale markets (Ballentine 2020), although they more often use virtual PPAs.

These benefits can also have positive impacts on local government renewable and clean energy projects that are not structured as large PPAs. Local governments purchasing renewables through vertically integrated utilities benefit when the programs can be structured to leverage wholesale market prices and provide customers with transparency (AEE 2021). Local governments developing on-site generation also benefit if these projects are able to access wholesale markets and earn additional revenues that make them more profitable.
Local governments are also interested in broader decarbonization outside of their own purchases. Organized wholesale markets broadly drive renewable energy development by integrating these resources into the grid more efficiently and optimizing their use. Organized wholesale markets can lower costs of renewable development when they provide improved access to transmission. In addition, well-coordinated regional planning may identify highvalue renewable energy projects outside of utility territories that may be missed through utility-led planning (Chen 2020). Coordinated regional planning balances generation resources over a wider geographic area so that diversity of size and location of variable resources can smooth out their variability (Sergici 2019). Organized wholesale markets can also develop sophisticated forecasts for future renewable generation, provide optimized power based on 
more granular regional supply and demand signals, share flexibility resources, and incentivize the retirement of inefficient plants (Chen 2020).

These benefits have led many states, utilities, and policymakers to pursue expansion or development of regional markets at the wholesale level as a driver for more efficient decarbonization of the electricity grid. The recent establishment of an energy imbalance market (EIM) in the western region is a key example of states and utilities pursuing increased market benefits. This emerging market allows power trading 4 among utilities in California and neighboring states as well as regional management of transmission congestion. Trading across a broader geographic area reduced renewable curtailment by 37,548 megawatt hours in the third quarter of 2020 alone (Market Analysis and Forecasting 2020). A regional market of some form is being considered in the Southeast following efforts in the North and South Carolina legislatures to study how a system operator could increase efficiencies. Utilities in this region are now considering a new regional exchange market that would facilitate trading (Peeler 2020) without providing the full benefits of an organized wholesale market (St. John 2020).

Organized wholesale markets are increasingly included in broad plans for decarbonization although reforms are needed to reduce clean energy barriers. Recent draft legislation released by the U.S. House Committee on Energy and Commerce, called the CLEAN Future Act, ${ }^{5}$ which sought a path to a 100 percent clean economy by 2050, suggested expanding wholesale power markets by requiring all electricity providers to join an RTO/ISO within two years (AEE 2020). In a recent analysis of how the United States can achieve 90 percent clean electricity by 2035 , wholesale market reforms-especially to better reward flexibility, accommodate federal and state clean energy targets, and remove barriers to clean technologies-were underscored as high-priority policy actions (Aggarwal and O’Boyle 2020).

\subsection{Organized Wholesale Market Barriers to Renewable Energy Development}

While organized wholesale markets are central to providing access to renewable energy and improving integration of clean energy technologies, barriers to clean energy development can arise if the markets do not adapt to changing technologies and goals considering their role managing the grid. Regulatory engagement is important to driving greater levels of decarbonization, and local government understanding of the development and impact of barriers is critical for effective regulatory engagement. Instead of fully detailing the specific barriers in each market, this paper provides a summary of where and how they arise: in rules and operational practices, within RTO planning functions, and in interaction with state policies. The following sections introduce these types of barriers at a high level and provide examples.

\subsubsection{Rules governing market participation and operational practices}

Market rules and operating procedures proposed by an RTO and amended through its stakeholder processes impact which resources can participate in the markets run by the RTO, what services they can provide, and how they are compensated for those services. These rules can impact the availability and price of renewable resources available for local government procurement as well as the pace of decarbonization in the RTO's region. To understand these issues, local governments should familiarize themselves with the types of markets their RTO operates, what the rules and operating procedures are generally, how they can become barriers, and the process by which they can be changed.

RTOs administer different types of markets, such as energy markets, ancillary services, and capacity markets (see Figure 2). Energy markets allow parties to secure electricity to meet consumer demand in the near term. A day-ahead market is used to procure energy based on projections, while a real-time market allows procurement to adjust for differences between projected and actual demand. Other markets for ancillary services maintain power quality and use energy to balance the system as it moves electricity from generation across the grid. Finally, only three RTOs (PJM, New York ISO [NYISO], and ISONew England [ISO-NE]) administer "mandatory" capacity markets as an approach to ensure that adequate resources are available to satisfy future customer load. Capacity markets are intended to incentivize the future availability of capacity by providing a mechanism to pay for that commitment. For renewable developers in organized wholesale markets, the ability of their projects to participate in these markets and earn revenues can impact the financial viability of their projects. Similarly, local governments working with developers may be able to structure more cost-effective projects if the developer can earn wholesale market revenues to develop additional revenue streams.

RTO tariffs and manuals contain market rules and operational practices that define how the RTO manages its markets and operates the grid. Market rules focus on 


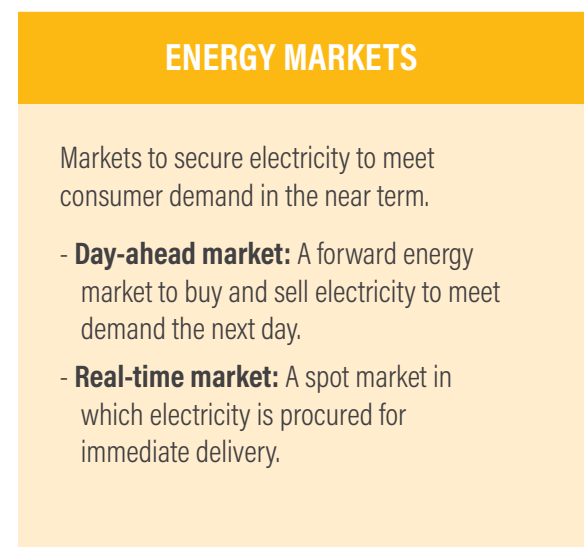

Source: Authors.

different elements of how energy markets are run, such as the prices for services, what resources can provide different services, and how costs for grid services are allocated among customers. Operational practices focus more on the operation of the grid and how the RTO maintains reliability.

Market rules and operational procedures can become a barrier to clean energy if they do not evolve to meet the changing needs of a decarbonized grid. RTOs rely on provisions that were developed when traditional large fossil fuel plants dominated these markets. New variable renewable resources or distributed resources operate very differently from traditional resources and require updated rules and procedures, a barrier that is well documented (Marcacci 2019; Wind Solar Alliance 2018). Here are three examples of updates needed to remove clean energy barriers:

\section{Participation models for new resource types.} FERC Orders 841 and 2222 (outlined in Table 1 in Section 2.2.4) require that RTOs update their rules to allow storage and aggregated DERs to participate in wholesale markets.

- Updated market product definitions. Rules that govern how energy products and services are sold and purchased may also need updating. Capacity, for example, is treated as an annual product, which does not align with the seasonality of solar resources. Clean energy advocates have argued that creating seasonal products would reduce barriers to solar energy (Wind Solar Alliance 2018).

\section{New methods for estimating contributions of resources. RTOs are exploring new ways to quantify the value new resources provide to the grid and comparing it with that of services offered by traditional fossil fuels. PJM, for example, is exploring the use of an effective load-carrying capacity (ELCC) method for calculating the capacity contributions of storage resources. The ELCC method quantifies the capacity a new resource can provide without an impact on reliability, allowing grid operators to understand a resource's capability in relation to the full portfolio of resources on the grid.}

The examples above illustrate how efforts to update these rules can be driven by FERC, requested by clean energy advocates, or led by RTOs themselves. In some cases, RTOs have created committees to directly address the benefits and challenges of renewables integration, such as PJM's Distributed and Inverter-Based Resources Subcommittee, which is focused on updating market rules to account for the new characteristics of solar-battery hybrid resources. Future work for this committee may explore reliability impacts of renewable resources and forecasting of behind-the-meter resources. Local governments engaging with their RTO on its efforts to integrate clean energy may be interested in the work done by committees such as these. If a special planning effort is not already underway, they can urge their RTO to set one up. Changes to both market rules and operational procedures require approval through the RTO's stakeholder process. We provide an overview of RTO stakeholder processes in Section 2. 


\subsubsection{Planning functions}

As the grid mix faces increasing renewable energy sources (which have characteristics different from those of fossil fuel generators), planning functions at the RTO level are important for integrating flexible loads, storage, demand response, and other complementary technologies. As the regional grid reaches high levels of wind and solar, optimizing these resources will require accounting for the complex interdependencies among quantities and locations and enabling transmission. Current market designs and RTO planning processes do not account for many of these critical system elements. If organized wholesale markets cannot adequately plan their systems to expand transmission, renewable energy development may stall. RTO planning also includes demand forecasting and development of target reserve margins, which impact the amount of resources developed in wholesale markets.

A key example of a planning function that can create barriers to renewable resources, transmission planning requires coordinated efforts by FERC, RTOs, utilities, and other stakeholders. While FERC sets guidelines RTOs must follow, each RTO develops its own planning cycles, processes, and stakeholder engagement. RTO transmission expansion planning was not designed to respond to demand for new renewable resources from corporate customers or local governments; transmission can become backlogged when planning cannot keep pace. In addition, the processes for considering new interconnections and network upgrades were not designed for a grid with many location-restrained renewable resources, often considered on a case-by-case basis, as opposed to broader planning, which would find efficiencies in regional upgrades. In MISO, renewable energy projects seeking transmission interconnection to come online have spent upward of 600 days in the transmission interconnection (Konidena 2020). A recent study found that nationally, the inefficient transmission planning and interconnection of projects had led to a backlog of 734 gigawatts in 2019 alone (Caspary 2021). Box 1 provides some basic background on transmission planning processes.

Similar to special committees charged with updating rules as renewables on the grid increase, RTOs can launch specific efforts to address planning challenges. In 2017, MISO launched a renewable integration impact assessment to inform future planning initiatives, such as MISO's Long-Range Transmission Planning Initiatives. The 2020 Long-Range Transmission Planning Initiative aims to find creative transmission and interconnection solutions, increase transmission investment to support renewables,

\section{Box 1 | Transmission Planning}

\begin{abstract}
Section 3 of this paper summarizes the stakeholder processes in each RTO that consider changes to market rules. Notably, additional stakeholder processes exist specifically for RTO planning functions, such as transmission planning.
\end{abstract}

RTOs develop transmission plans using a standing body of planning staff who provide modeling and analysis, sometimes with additional expertise from external consultants. These planning cycles may recur every 16 months to 3 years (ISO-NE, the exception, does not have set planning cycles). Stakeholder involvement is included in the planning process but varies across RTOs. Individual transmission plans and stakeholder input are reviewed by planning staff, who then analyze regional needs and economic impacts. Generally, a committee at the RTO (such as a planning, markets, or transmission expansion committee) will review proposed plans. Final approval of plans generally requires signoff from the RTO board (Eto 2016).

In planning for future transmission needs, planners develop future scenarios that account for transmission needed to integrate renewable resources. Much of this planning, depending on the RTO, is focused on need projected by utilities or by projects already in the interconnection queue. Like corporate renewable energy purchasers whose demand may not be captured by these processes, local governments can play a role in communicating their plans and goals to their RTO to reduce the chance that lack of transmission becomes a barrier to their purchases (Wind Solar Alliance 2018).

and increase flexible resources. Utilities can also play a role in advocating for change. The CapX2050: Transmission Vision Report is a joint effort by transmission-owning utilities in MISO to identify transmission challenges that need to be overcome to transition to a grid with higher levels of wind and solar (CapX2O20 2020). FERC can also play a central role in addressing these challenges. Clean energy advocates have called on FERC to release a new nationwide transmission planning and cost allocation rule to reform both regional and interregional transmission planning (Caspary et al. 2021).

\subsubsection{Interaction with state policies}

In recent years, conflicts between state policies for clean energy and wholesale market price formation have become a considerable challenge for renewable energy development within RTOs that have mandatory capacity markets. Generation owners within these RTOs have argued that state policies to incentivize renewable energy, such as renewable portfolio standards or direct procurement of renewable resources through bilateral contracts, cause price distortion within the markets as they allow 
renewable energy to receive payments that are outside of the market and therefore bid in lower costs. Others have identified plummeting prices for natural gas as another factor also depressing prices in wholesale markets. This conflict can be seen in PJM, ISO-NE, and NYISO, where "buyer-side mitigation rules" are currently being used to target state incentives for clean energy and potential impacts on wholesale market auction results.
In PJM, for example, FERC has expanded the scope of the Minimum Offer Price Rule (MOPR) to impact renewable energy bids, determining that the rule is needed to correct the disconnect between state incentives and price formation (see more details in Box 2). The more stringent MOPR has increased uncertainty over future market revenue and delayed capacity auctions, impacting the developers from whom local governments purchase renewables.

\section{Box 2 | Minimum Offer Price Rule (MOPR)}

In December 2019, FERC issued an order directing PJM Interconnection to expand its MOPR to include new and existing capacity auction resources, of all fuel types, that receive state subsidies and mitigate the impact of these resources on the capacity market. The order is intended to correct the price distortions in PJM's capacity market that some stakeholders argue exist because of state subsidies for clean energy resources, which they claim effectively raise the price for all new resources bidding into the market, leading to higher customer bills. The MOPR artificially inflates the prices of new renewable energy bidding into capacity markets, potentially stagnating the growth of renewable energy resources, as they are less likely to be selected or cleared by the capacity markets.

\section{FIGURE B1 | PJM Electricity Capacity Market: Before and after changes to the MOPR}

BEFORE CHANGES

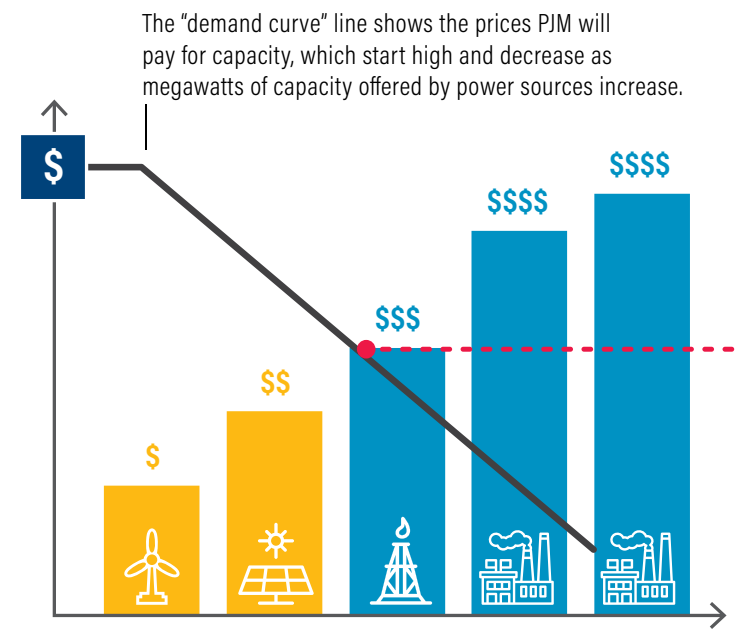

Megawatts of capacity offered

With state-supported sources like solar and wind offering low-cost electricity generation capability in PJM's capacity market, the clearing price that all sources get paid for capacity is set lower, which helps keep capacity costs down.
AFTER CHANGES

The "clearing price" is set at the point where the total capacity offered hits the demand curve.

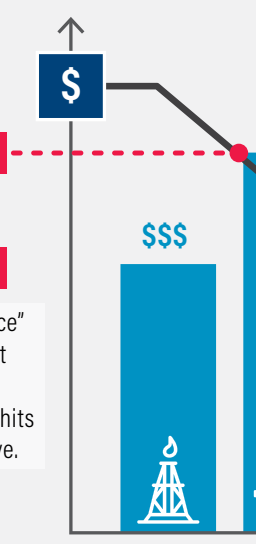

\$\$\$

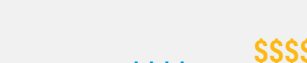
$\$ \$ \$$ \$\$S\$ $\$ \$ \$ \$$

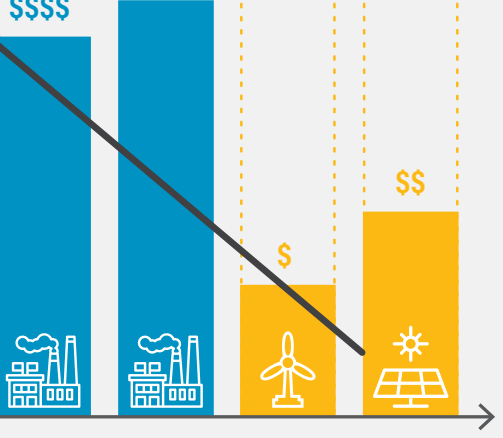

Megawatts of capacity offered

Capacity costs from state-supported resources are artificially inflated by a requirement that they offer at or above high "minimum price." This restricts market competition and raises the clearing price, increasing costs for customers.

Source: Image courtesy of Creative Commons, https://creativecommons.org/licenses/by-nc-nd/4.0/.

Local governments within the PJM region working on solar energy deals have already been affected by the proposed MOPR, as increased uncertainty over future market rules and delayed capacity auctions have impacted the developers local governments work with. Some local governments have seen projects stalled or canceled, threatening their ability to meet their goals and increasing the development costs of projects that do move forward. Local governments have much broader concerns related to the impact on constituents they represent. Recent analysis estimated that changes to the MOPR could lead to consumer impacts estimated at between $\$ 1$ billion and $\$ 2.6$ billion annually (Goggin and Gramlich 2020). 
Because of this conflict, individual PJM states have explored exiting PJM's capacity markets and creating alternatives for state-driven resource adequacy. The Organization of PJM States Inc. (OPSI), described in Section 3.1, recently sent a letter to PJM's board outlining concerns and recommendations for the evolution of market design in the PJM region. These recommendations included allowing states to retain primary authority for meeting resource adequacy, and accommodating state procurements, policy choices, emission levels, or clean energy requirements (OPSI 2021). Similar conflicts have arisen in ISO-NE, which has a rule in place (very similar to the MOPR) that creates price floors for resources bidding into the capacity market through an "offer review trigger price" (Walton 2020b). In 2021, the New England States Committee on Electricity (NESCOE), also discussed in Section 3.1, released a vision statement calling for reform of ISO-NE markets to support states' clean energy laws as well as reform of transmission and governance (NESCOE 2020). Even as a single-state RTO, NYISO has had similar conflicts that could lead to development of a new system for acquiring capacity in a way that is aligned with state energy goals (Walton 2020a; Sustainable FERC 2020).

Similarly, discussions are underway related to RTOs' ability to incorporate state carbon pricing into the organized wholesale markets. Many states in PJM are already members of the Regional Green House Gas Initiative (RGGI), which has allowed them to coordinate a market-based carbon-reduction program and invest proceeds in energy efficiency, renewable energy, and other programs benefiting consumers. States see the carbon-reduction program as a key pathway to developing a clean energy economy and creating new green jobs. PJM has recently developed a Carbon Price Task Force that is exploring ways for the RTO to help mitigate leakage ${ }^{6}$ between RGGI and nonRGGI states. NYISO is exploring models for administering a carbon price within the wholesale market itself. Moving forward, harmonizing state carbon-pricing and wholesale market functions may impact local government goals and strategies as well. In September 2020, FERC held a technical conference on examining the role of RTO markets in state-determined carbon pricing in response to stakeholder requests. Shortly afterward, it issued a policy statement asserting that FERC's jurisdiction includes incorporating state-determined carbon prices into RTO markets and requested comments on what factors it should consider when evaluating such proposals (FERC 2020a).

In Section 2 we walk through the engagement pathways that local governments can follow to become more engaged in issues at the wholesale market level, many of which apply to states as well. Section 3.1 also provides details on how states engage with their RTO and their relationship with it as a specific stakeholder group.

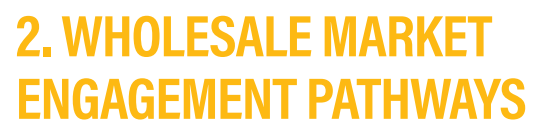

Local governments that want to engage at a high level in the wholesale market issues described in Section 1 can choose from several engagement pathways that are not mutually exclusive. These engagement pathways can be organized as public comments and actions, actions at the FERC level, and actions at the RTO level. In the following sections, we review these pathways and their related activities. Figure 3 provides a high-level overview of these pathways and two of the considerations related to each. We indicate whether the action is likely to have a direct impact (in that FERC or RTO staff are very aware of the action and it is part of their decision-making or the public record) or a broad impact (in that the local government may gain more information or share views, but this may not have a strong influence on FERC or RTO decisionmaking). More direct actions also tend to be more formal or time-consuming, and we touch on these elements in the explanations of the pathways below. We do not specifically call out the level of effort required by a local government to engage in each pathway related to each action, as this can be highly variable. We do highlight the collaborative potential across almost all of the pathways, as this can be an important avenue to overcome capacity barriers.

Local governments interested in developing an engagement strategy will need to do their own analysis of each pathway's impact and required effort, considering their specific context, and treating our considerations as an introduction. ${ }^{7}$ Broader long-term city goals, for example, are an important consideration for local governments. Local governments may choose to focus on engaging on issues that align with their comprehensive or master planning. Pathways such as direct engagement may be appropriate if the local government also has a long-term goal of developing relationships with regulators or their RTO. Partnerships may make sense if the local government wishes to work more closely with other clean energy advocates. Local governments may also choose to focus on engagements where their input on an issue is unique. For example, engagement to address barriers to a local government's ongoing efforts to procure renewables to meet municipal load could be a good way to make those barriers known more broadly to market stakeholders and 


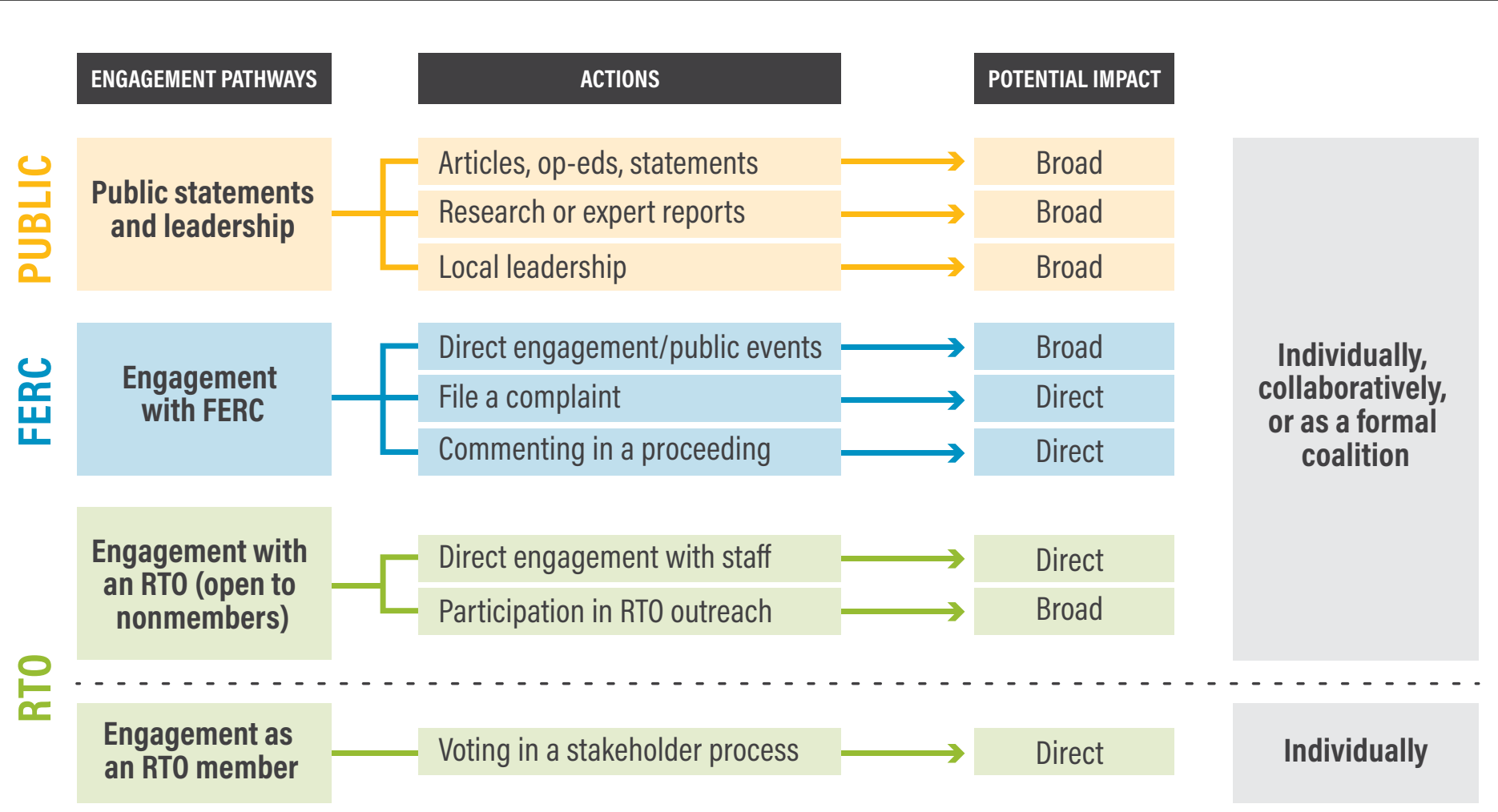

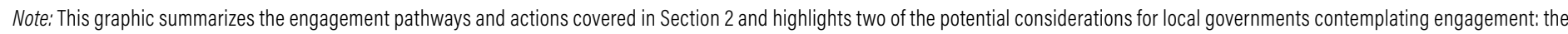

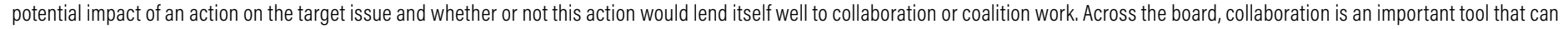
help local governments overcome engagement barriers.

Source: Authors.

decision-makers. For broader issues where local governments are aligned with other active stakeholders, simply signaling support may be a good way to support these efforts without investing a lot of time and effort.

\subsection{Public Statements and Leadership}

Along the public statement and leadership pathway, nonmember stakeholders can comment on RTO issues through op-eds, policy statements, and educational materials, or by providing comments in other venues such as symposiums or conferences. These actions are summarized in Figure 4. Commenting on issues outside of the stakeholder or outreach processes provides local governments with more flexibility to craft messages that meet their needs and to work on a more flexible time frame, perhaps reducing the effort needed to comment. Like other engagement pathways, local governments should weigh the level of effort against the potential impact.
Public statements outside of the stakeholder process can allow local governments to reach a wider audience, such as potential partners or other stakeholders in need of education on the issues. However, it may also reduce the chance that RTO staff is aware of the comment, which will not be placed in the public record created by these processes.

While public comment is generally thought of as easier but less impactful than formal comment, there can be exceptions to this rule of thumb. For example, a policy statement may be easier for a local government to develop compared to a formal FERC or RTO filing; however, it may have similar impact as a filing if other stakeholders cite it in their filings, thus drawing it into the public record. An expert report on an issue, as another example, may require more effort than a formal filing alone if it requires local governments to work with consultants and produce a formatted and detailed piece of research. This 
type of public statement, however, may provide its own benefits related to impact if it is able to provide compelling data or arguments that a shorter piece would not. As a final example, if local governments choose to sign on to statements that other relevant stakeholders (such as states, consumer advocates, environmental groups, public interest groups, or corporate renewable energy purchases) have already developed, formal comment may actually be quicker than drafting a detailed public statement outside of a formal proceeding or process.

Finally, local governments can lead their communities by drawing attention to the role their local RTO plays in either helping or hindering clean energy development and providing education on these topics. As local governments begin to take a leadership role in addressing these issues, they can collaborate with a wider set of other local governments to strengthen this voice. Local government leadership can also extend to working with other local public institutions or commercial entities. For example, the City of Philadelphia has made progress toward its goal of a 100 percent carbon-free electricity grid by 2050 through renewable power purchase agreements. While still working on this goal, it established the Climate Collaborative of Greater Philadelphia, which invites businesses and other public institutions to leverage lessons from this experience and work collectively toward decarbonizing the region. Cities have become clean energy leaders in terms of setting and achieving goals. Expanding this role to regulatory engagement can maximize the impact of their work.

\subsection{Engagement at the FERC Level}

Organized wholesale markets, with the exception of ERCOT, ${ }^{8}$ are all regulated by FERC. The pathways for engaging at the FERC level include participating in FERC's public events, filing official complaints, or engagement in FERC proceedings. Engagement in FERC proceedings can cover a lot of different actions, such as filing comments on issues addressed in notices of inquiry or technical conferences, or proposed rules, or submitting protests or supportive comments regarding requested rule changes. These actions are summarized in Figure 5 . There are other ways for local governments to engage, but these three actions are easy to understand and relevant to local governments seeking to remove barriers through FERC regulation of RTOs. This section includes a quick introduction to FERC composition, authority, and roles, to help local governments understand how different stakeholders can interact with FERC and the types of actions FERC can take.

\section{Figure 4 | Public Statements and Leadership Engagement Pathway}

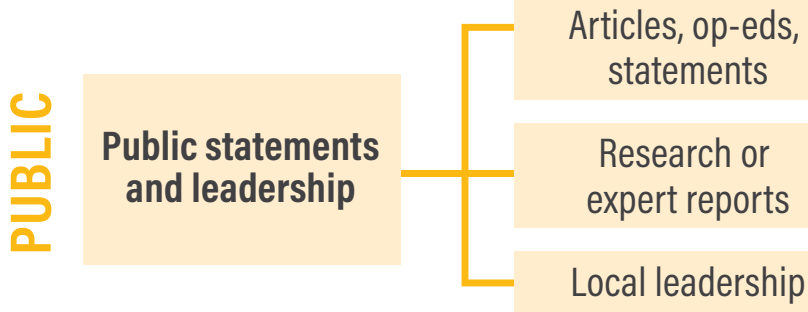

Note: Public statements and leadership can be effective ways to quickly and easily comment on issues at the FERC or RTO level impacting local governments. These comments can also be crafted to help other parties more fully understand local government action, such as clean energy goals and renewable energy purchasing. Public comments and leadership can also reach a wider audience and engage new voices to drive broader regional decarbonization.

Source: Authors.

Figure 5 | Pathway for Engagement with FERC

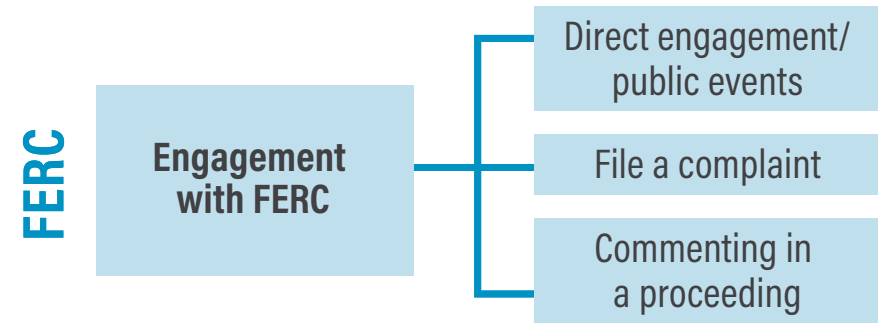

Note: FERC-level engagement can impact the regulation of the RTO that local governments are operating in and address broad issues impacting all RTOs. Engaging at the FERC level requires local governments to understand the roles of the agency and the types of actions and proceedings that drive change. Direct engagement or formal complaints may raise new concerns or issues. Several wholesale market-level issues are addressed through proceedings that offer several opportunities for stakeholders to file comments on the public record.

Source: Authors.

\subsubsection{Understanding FERC's composition, authority, and roles}

FERC is an independent regulatory body and federal agency composed of a five-member commission appointed by the U.S. president, with the advice and consent of the Senate. All commissioners hold office for a term of five years but can be removed on the grounds of inefficiency, neglect of duty, or malfeasance. If a commissioner is 
appointed to fill a vacancy occurring prior to the expiration of the term for which the predecessor was appointed, the commissioner shall only be appointed for the remainder of the term. Among the five members on the commission, there cannot be more than three members from one political party.

The president also appoints one of the members of the commission to be the FERC chairman and act as administrative head of the commission. The FERC chairman is responsible for setting the agenda of the commission, makes decisions on what issues move forward to hearings, and decides whether the commission votes on orders if voting is not statutorily mandated. The chairman of the commission can also designate any other member of the commission as acting chair in the chairman's absence. Each member of the commission, including the chairman, is allowed to have one vote. The decisions of the commission are determined by majority vote of members present.

FERC is accountable to the U.S. Congress, where commissioners and senior staff routinely testify before various committees. For this reason, local governments and other stakeholders could consider engagement with Congress if they felt FERC regulation was not just and reasonable.

FERC's authority originates from the Federal Power Act (FPA). Section 201 of the act grants FERC jurisdiction over transmission and interstate wholesale power trading. Box 3 outlines some considerations for FERC jurisdiction and the evolution of the utility industry that may be helpful for local governments as they learn about the role of RTOs and FERC.

FERC's authority over interstate power trading creates responsibility in approving or denying RTO tariffs and its ability to remedy unjust and unreasonable rates. Under Section 205 of the FPA, FERC must ensure that rates under its jurisdiction are "just and reasonable and not unduly discriminatory." Under Section 206, FERC must "remedy" any rates that are "unjust, unreasonable, or unduly discriminatory," giving it leeway to initiate reforms when needed. These statutes also provide important avenues for parties to request change at the FERC level or for FERC to initiate change, including changes to RTO governance documents. Which parties hold 205 versus 206 rights varies across RTOs, but this is an important consideration because a 206 filing requires a higher burden of proof, as the complainant must argue that the existing rates are unjust and proposed solutions are just (James et al. 2017).
Box 3 | Shifting State versus Federal Jurisdiction over Energy Issues

The Federal Power Act (FPA) was written in 1935 for FERC's predecessor, the Federal Power Commission, and created the distinction that federal jurisdiction was limited to interstate transmission and power trading at the wholesale level and that states retain jurisdiction over generation, local power distribution, intrastate power trading, and power used by "the transmitter." For some time, this distinction has been considered a "bright line." As the utility industry has evolved, including the creation of RTOs and ISOs through FERC Orders 888 and 2000 and other proceedings, the bright line has become harder to maintain (FERC 2020d).

While the FPA still provides the basis of FERC jurisdiction, technology has also advanced alongside market structure and significantly altered how we generate and use electricity. The emergence of electricity storage technology is a key example of a technology change that can complicate the definition of state versus federal issues. Storage technologies have the capability to provide multiple services across the traditional generation, transmission, and distribution levels. Similarly, demand response allows retail consumers to shift their electricity consumption based on price signals and provide services in wholesale markets. Other issues, such as net metering, transmission planning, and state clean energy goals, also complicate jurisdictional issues (Dennis et al. 2016).

Market evolution will continue to create new energy products and services that straddle state and federal regulatory structures and potentially lead to jurisdictional disputes. For now, questions of federal or state authority under the FPA are resolved on a case-by-case basis. FERC and states have collaborated on overlapping topics in the past through joint collaboratives and could hold joint hearings on topics. For local governments, being aware of questions around jurisdiction can provide helpful context when deciding how and if to engage at the RTO or FERC level.

Appendix B provides links to primers on FERC if local governments want to fully understand its roles, which also involve public utility mergers, reliability standards, investigation of market manipulation, licensing of new hydro plants, regulation of natural gas pipelines, and other activities.

\subsubsection{Direct engagement and participation in public FERC events}

FERC commissioners can meet directly with stakeholders to discuss wholesale market issues as long as no open docket is related to these issues. Once a docket that intervenors may participate in is open, FERC ex parte rules prohibit off-the-record conversations with any FERC staff member on topics related to contested proceedings in order to avoid discussions that might give one party an 
advantage over the other. Local governments might be interested in having discussions like this to communicate how they are impacted by issues at the wholesale market level that commissioners might not be aware of and/or to support potential FERC-level changes. As direct engagement is also an option for RTO-level engagement, we provide a longer discussion of the benefits and drawbacks of direct engagement in Section 2.3.1.

Public FERC events provide avenues for local government engagement that do not require a significant time commitment and provide education on important issues, most notably technical conferences hosted by FERC. Technical conferences are events on specific proceedings or broad topics that FERC can use to foster conversations and publicize new information in a transparent setting. When related to a specific proceeding, technical conference can allow parties to discuss comments filed in the proceeding while allowing all interested parties to join. Recent technical conferences topics have included "Impacts of COVID19 on the Energy Industry” (docket no. AD20-17-00o), "Hybrid Resources" (docket no. AD20-9-000), "Carbon Pricing in Organized Wholesale Electricity Markets" (docket no. AD20-14-000), and "Offshore Wind Integration in RTOs/ISOs" (docket no. AD20-18-000). On its website, FERC issues a notice announcing the conference as well as an agenda for events. In some cases, stakeholders can nominate themselves as potential speakers. This type of public participation is similar to engagement in RTO stakeholder outreach. The impact of both direct engagement with FERC staff or participation in public events can be considered less direct than other actions because these actions are likely to center on high-level issues (sometimes spanning several RTOs) and are not tied to any formal decision-making process.

\subsubsection{Formal complaints}

FERC offers a formal process for filing complaints regarding aspects of the commission's regulation of the energy industry and markets, including challenges to specific RTO market rules. Anyone interested in seeking commission action may file a complaint against any person "alleged to be in contravention or violation of any statute, rule, order, or other law administered by the Commission, or for any other alleged wrong over which the Commission may have jurisdiction" (FERC 2020b). To file complaints, FERC encourages electronic submissions using the eFiling online tool. It allows individuals to mail complaints to FERC offices and provides guidelines on what informa- tion to provide in the complaint. Pending complaints are docketed, and FERC issues a public notice of new complaints. While formal complaints can require only minimal staff time to draft and submit the material, if taken up by FERC this could lead to local government engagement in a proceeding.

\subsubsection{Commenting in FERC proceedings}

Most commonly, progress on issues at FERC happens within docketed proceedings the commission has opened on specific issues. These compliance-filing processes allow FERC to issue directives on changes needed to RTO rules, establish a timeline for RTOs to meet these changes, allow for stakeholder and market participant feedback, and then finalize changes. FERC often announces new proceedings or approves filings through FERC orders filed in these proceedings. Table 1 provides examples of recent FERC orders in rulemaking dockets that impact all RTOs. FERC may also direct orders to individual RTOs and their specific market rules. Dockets are available to the public through FERC's eLibrary tool, which posts public filings within dockets, including FERC rulings and intervenor comments. Docket number prefixes indicate what kind of proceeding is being undertaken. For example, a docket starting with "RM" is a rulemaking docket, "AD" is an administrative, and "ER" an electric rate case. More details on other types of proceedings can be found on the FERC website. Educational resources related to FERC are found in Appendix B.

FERC sometimes uses a notice of inquiry to solicit input on a specific topic and a notice of proposed rulemaking to both signal potential action and collect input. Rulemaking dockets are generally separated into four phases: petition for rulemaking, notice of proposed rulemaking, notice of final rulemaking, and, if needed, a rehearing of rulemaking (FERC 2020d). A petition for rulemaking can be filed by parties from the energy industry, companies, stakeholders, or the general public. When the commission has made a decision, it will issue a final rulemaking order outlining the action it is taking. Stakeholders seeking to challenge a final rulemaking can request a rehearing; if the request is rejected by FERC, stakeholders may petition for review by the U.S. Court of Appeals. After a final rulemaking, stakeholders may also petition FERC to issue a declaratory order if they feel further explanation is needed to determine the rule's impact. 
FERC Order 2222: Participation of Distributed Energy Resource Aggregations in Markets Operated by Regional Transmission Organizations and Independent System Operators (2020)

Docket: Docket no. RM18-9-000

Highlights: Requires RTOs to allow aggregated distributed energy resources (DERs) to compete in wholesale energy, capacity, and ancillary services markets. DERs are defined by location on the electric grid, on the distribution system, and behind the customer meter, and not technology allowing rooftop solar, batteries, electric vehicles, and other resources to participate. RTOs may not develop rules that limit technologies from participating.

FERC Order 872: Qualifying Facility Rates and Requirements Implementation Issues under the Public Utility Regulatory Policies Act of 1978 (2020)

Dockets: RM19-15-000, AD16-16-000

Highlights: Revised the commission's regulations implementing the Public Utility Regulatory Policies Act of 1978, which required utilities to purchase renewable energy from small facilities if lower cost than their own production. Modifications adjusted the size requirements of these facilities and distance between affiliated facilities to count as a single qualifying facility.

FERC Order 841: Electric Storage Participation in Markets Operated by Regional Transmission Operators and Independent System Operators (2018)

Dockets: RM16-23-000, AD16-20-000

Highlights: Requires RTOs to update market rules and operations to allow for storage, to participate in wholesale energy capacity, and ancillary services markets. Required changes included establishment of a common definition for storage, a higher minimum size for storage projects, and a requirement that market rules recognize the unique operating characteristics of storage.

Note: These examples showcase rulemaking dockets that cut across several RTOs, since these types of reforms might be of interest to local governments as they drive changes across markets. As local governments consider the specific rules their RTO develops, being able to compare them to approaches other RTOs are taking may be useful.

Source: FERC (2020c).

Stakeholders, such as local governments, may choose to participate in a FERC proceeding, such as a rulemaking docket, in order to share their comments, concerns, or any other information they feel is relevant to FERC as it makes its decisions. In rulemaking, administrative, or general policy cases, local governments can submit comments without having to petition for intervenor status at FERC. Motions can be filed through FERC's eFiling tool, which allows stakeholders to search for specific dockets and file their requests electronically. Being granted intervenor status grants stakeholders access to join the service list and receive notices regarding the filings of other parties in the docket, ${ }^{9}$ allows them to file their own statements, and affords them the opportunity to request a rehearing. Intervenors need to sign up for FERC's eRegistration account and follow guidelines on acceptable file formats and sizes. Comments related to FERC proceedings can take several forms, such as commenting on issues addressed in notices of inquiry, requesting a declaratory order, commenting on proposed rules, and submitting protests or comments supportive of requested rule changes. Local governments may be able to have direct impact on an issue by putting their position on the public record, but they may also face a steep learning curve as they become familiar with FERC's proceedings and the mechanics of commenting.
Working with partners who are already familiar with these issues and with avenues for engagement or securing support from an expert can be helpful in overcoming these barriers.

\subsection{Engagement at the RTO Level}

While FERC engagement provides insight into the regulation of RTOs, engagement directly with an RTO provides much deeper access to the processes driving market changes, the views of the RTO's membership, and the RTO's opinions on issues. Pathways for engaging at the RTO level include direct engagement with staff, participation in RTO outreach as a nonmember, or participation in RTO stakeholder processes as an official member, possibly with voting rights as well. These actions are summarized in Figure 6. Direct engagement or participation in RTO outreach can be easy first steps for local governments new to engagement at the wholesale market level, but the impact of these actions may be harder to quantify than official membership and voting. The impact of membership and voting, however, depends on the stakeholder processes and governance within each RTO, including the relative power of each stakeholder type in decision-making. 
Figure 6 | Pathways for Engaging at the RTO Level

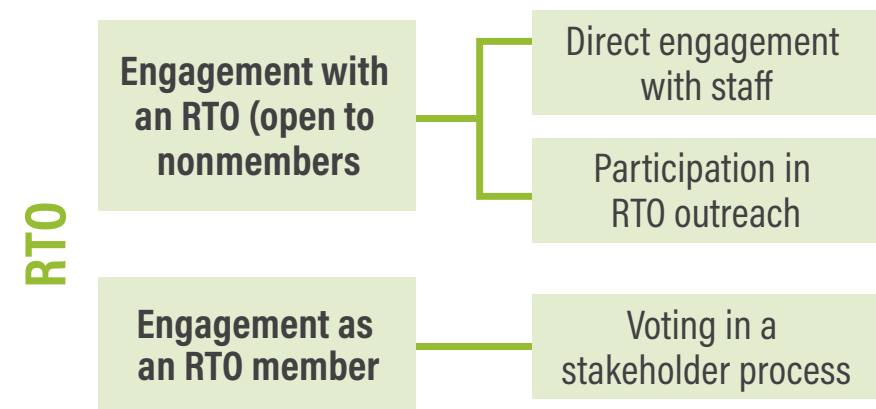

Note: RTO-level engagement can directly impact the regional electricity market local governments operate within and require knowledge of the RTO's governance and stakeholder processes. Local governments can approach engagement in terms of the actions they can take without being a voting member and compare this with what official membership in their RT0, possibly with voting rights, provides. While voting may have direct, quantifiable impact, it should be considered carefully as a strategy considering the associated cost and complexity.

Source: Authors.

\subsubsection{Direct engagement with RTO leadership or staff}

Local governments can engage in wholesale-level issues by pursuing direct discussions with staff at their RTO on topics of interest. Local governments may engage directly with RTO leadership or other more technical staff depending on the topic and availability within the RTO. When possible, communication with leadership may be useful if local governments are sharing high-level messages or requesting specific actions. Potential representatives best suited to participate in these discussions may be staff in leadership roles related to membership and client relations, state relationships, or other external affairs. These representatives can also play an important role in connecting local governments to others within the RTO who work on more specific issues or in providing information on options for more engagement. Discussions with technical staff may be useful if local governments are looking for detailed information on RTO activities. RTO staff may provide outreach to various stakeholder groups on key issues or provide educational presentations directly to coalitions.

This type of engagement can provide some key benefits over other avenues in terms of content flexibility and relationship building. When engaging in RTO governance processes or in FERC proceedings or events, local governments will need to tailor their messages to respond to topic areas where feedback has been requested and work on the timelines set by others. In one-on-one discussions, however, local governments may be able to communicate their needs broadly or specifically, depending on their interests. This may allow them to establish a dialogue that enables RTOs to better understand local governments as a stakeholder type and their unique needs. For both RTOs and local governments, an open dialogue can improve the relationship between the two and potentially help them identify areas to develop collaborative solutions.

A drawback of direct collaboration with RTO leadership is that it provides private communication and therefore is much less visible to others, which may increase or reduce the value for local governments. For issues or perspectives where local governments are interested in having their input captured in the public record, pursuing participation in RTO/FERC processes and outreach or making public statements can be helpful. Local governments should be aware that Freedom of Information Act laws apply to FERC, states, and cities but do not apply to RTOs. RTOs determine their own level of open meetings and transparency.

Finally, participation in formal processes covered in sections below provides additional benefits that direct engagement does not by allowing local governments to support transparent and inclusive RTO governance more broadly. Improving governance models and stakeholder outreach can pave a way for more interested parties, including local governments, to provide input on barriers to renewable energy. If local governments find that RTO governance and stakeholder relations are not conducive to addressing solar barriers in markets, improving transparency, accountability, inclusiveness, and responsiveness or removing barriers to participation could be helpful. Many of these governance elements are required by FERC Order 719 (Gardner 2019), which sought to improve "the responsiveness of regional transmission organizations (RTOs) and independent system operators (ISOs) to their customers and other stakeholders," among other goals.

\subsubsection{Engagement in RTO stakeholder outreach as a nonmember}

Local governments have several opportunities to engage with their RTO on market issues without becoming a formal member-mostly by participating in public meetings and using RTO outreach materials. Similarly, local governments can also comment broadly on the impact of market rules in their own publications or in public forums or communications. While these types of engagement do not involve directly communicating with marketlevel decision-makers through official channels, they 
typically require fewer municipal resources to complete and can be used to share city input and needs with a broader audience.

To increase transparency and facilitate engagement, RTOs make many of their meetings public, sometimes event board meetings, to nonmember stakeholders. The RTO may also host meetings that specifically reach out to stakeholders. Twice a year PJM offers public general sessions that address broad industry issues through speakers and panel discussions. CAISO hosts an annual stakeholder symposium in addition to specific targeted forums such as the Renewable Energy Issues Forum in 2019 or the Energy Storage and Aggregated Distributed Energy Resource Education Forum in 2015. The emerging Western Energy Imbalance Market holds three public regional issues forums that allow for discussion of broad topics not yet covered by a stakeholder process.

Nonmembers also can often participate in stakeholder meetings or the identification of issues. NYISO's bylaws allow public attendance at all stakeholder meetings if it is in-person and preregistered with the secretary, although the public cannot participate unless the ISO requests input. PJM stakeholder training illustrates how external entities can raise concerns during issue identification in Figure 7. PJM's manual, for example, highlights that external stakeholders and nonmembers can attend meetings and raise issues for the stakeholder process to address, although the secretary of the Members Committee and the appropriate committee chair and secretary can use their discretion as to whether or not to add the item to the agenda. During the Problem Investigation process shown in Figure 7, nonmembers can also comment as part of the "Identify and explore interests" step. Stakeholders are encouraged to describe their organization's core interests and their interests in the matter at hand when raising an issue to be addressed.

When an issue is addressed by an RTO with enough transparency that nonmember stakeholders can follow the status of a proposed new rule, they can provide informal comment by making public statements about the issue or sending public letters to the parties involved. PJM maintains a public list of all letters sent to its board and encourages stakeholders to comment on market design or operations, reliability operations, or planning. It's not uncommon for PJM leadership to publicly comment on the steps they are taking on the issue and how stakeholders can be involved.

\subsubsection{Engagement as an RT0 member stakeholder}

In RTOs where it is possible for local governments to vote in decision-making processes, this pathway for engagement can also provide the most tangible impact on wholesale market issues. However, engaging at the RTO level by becoming an official stakeholder with voting rights within RTO stakeholder processes entails likely the biggest commitment among all of the engagement pathways in terms of cost, time, and the need to fully understand the role of stakeholders within the broader governance model. To better understand the roles local governments could take on as voting members and the impact these roles could have, we first provide general background on RTO membership and governance models. We also include specific information on the potential financial implications of this engagement pathway, as they are easier to quantify than in others. Finally, when considering this pathway, local governments may also consider other stakeholders engaged at this level and the relative impact of each group's participation in terms of voting power or influence.

\subsubsection{RTO MEMBERSHIP CATEGORIES AND MEMBERSHIP COSTS}

RTO stakeholders are generally organized into member "sectors," such as transmission owners, electric generators, end-use customers, public power entities, consumer advocates, and environmental groups. Local governments that are considering joining their RTO as voting members (but that are not municipal utilities) may find the end-user sector the most appropriate category to join. As long as an entity meets the criteria for a stakeholder group, it can formally apply for membership. In addition to defining stakeholder groups, RTOs may separate out different types of membership levels, such as voting members versus nonvoting members. The stakeholder group local governments most often fit, the end-user sector, is considered a voting member across RTOs. Local governments could explore new membership categories in the future if current options don't meet their needs.

Active participation in stakeholder meetings can be time-consuming, as RTOs can host hundreds of meetings per year (James and Jones 2017) and work on specific topics can take years. It is not uncommon for stakeholders to enlist subject matter experts or consultants to help manage their participation in these groups and sometimes share these consultants across several groups to defray costs. Additional costs may include travel to attend in-person meetings, which can be a burden on limited budgets or local governments with restricted 


\section{PJM ISSUE IDENTIFICATION}

\begin{tabular}{|c|c|c|c|}
\hline Issue source & $\begin{array}{l}\text { How is the issue identified in } \\
\text { the stakeholder process? }\end{array}$ & Initial screening & Ultimate decision-making \\
\hline $\begin{array}{l}\text { External } \\
\text { - Operations } \\
\text { - Other Federal Regulator } \\
\text { - State Regulator } \\
\text { - State Legislature } \\
\text { - NERC or Reliability Council }\end{array}$ & $\begin{array}{l}\text { Internal Source - Member } \\
\text { - Letter from Members to PJM } \\
\text { staff or Board (would then likely } \\
\text { be presented to committee by } \\
\text { Member or PJM Staff) } \\
\text { - Proposal to committee }\end{array}$ & $\begin{array}{l}\text { - Member decides which committee } \\
\text { may be appropiate for review } \\
\text { - Member contacts staff and } \\
\text { requests committee } \\
\text { - Presentation to committee } \\
\text { - May bring up issue during } \\
\text { a meeting }\end{array}$ & $\begin{array}{l}\text { - Retain issue } \\
\text { - Assign to another existing } \\
\text { standing committee, task force, } \\
\text { or subcommittee } \\
\text { - Create a new subcommittee, task } \\
\text { force, or special team } \\
\text { - Decide not to take up the issue }\end{array}$ \\
\hline
\end{tabular}

\section{CONSENSUS-BASED RESOLUTION PROCESS}

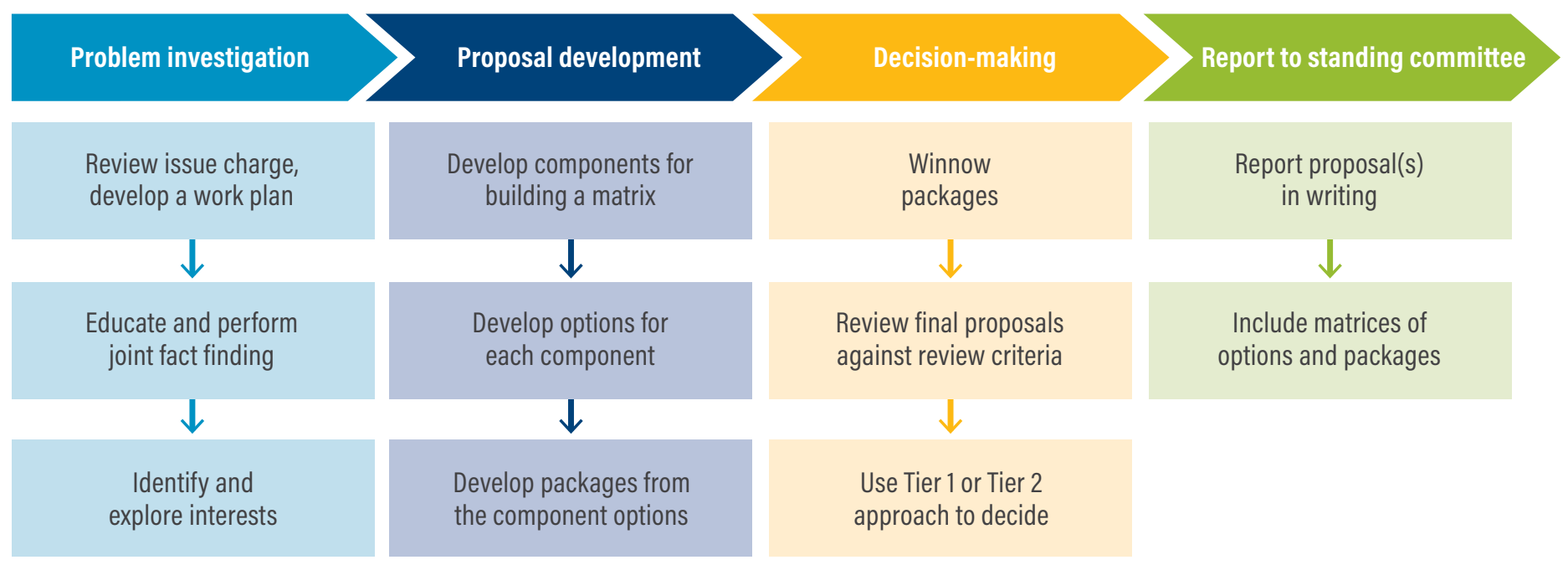

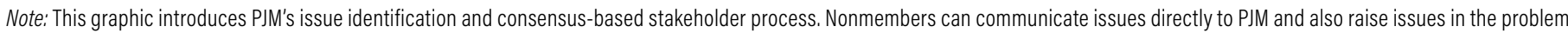
identification phase.

Source: PJM (2019); Anders and Fabiano (2019) 
travel budgets. Box 4 provides additional examples of the financial considerations related to membership, including membership dues.

\subsubsection{GOVERNANCE MODELS}

RTO governance models influence the engagement options for local governments in terms of the impact of their participation and the timing and procedures they must follow. RTOs have three types of stakeholder-governance models: advisory-only, shared governance, and governor-appointed boards.

Advisory-only: In advisory-only stakeholder processes, the RTO board of directors has ultimate authority over market-rule changes although proposed rules move through a stakeholder process to collect input. ${ }^{10}$ When market-rule changes are submitted to FERC, stakeholders have the opportunity to comment or protest within that proceeding, even if they already engage at the RTO level. The advisory-only model is followed in MISO, ISO-NE, and the Southwest Power Pool (SPP). ERCOT's model is very similar to the advisory-only model in that the board considers stakeholder input; it does not submit changes to FERC, however, as it is overseen by the Public Utility Commission of Texas.
Shared governance: NYISO and PJM follow a shared governance model where both the stakeholders and board of directors agree on a proposal before it is submitted to FERC.

Governor-appointed board: CAISO is unique in that the governor appoints a five-member board to review proposals for filing to FERC. Unlike with other RTOs, stakeholder involvement at CAISO is an informal notice and comment dialogue on major contested policy issues with no voting (James et al. 2017).

A full review of the governance models of each RTO is beyond the scope of this paper. However, local governments interested in becoming members can find membership materials and governance documents on the website of their RTO (see Appendix B). Governance materials vary; for example, the ISO-NE stakeholder process can be found in its participant agreement, while PJM's is outlined in its operating agreement. Studying the roles of the board of directors, standing committees of the board, and any advisory committees can help local governments understand how decisions are made and which groups they may interact with. Figure 8 illustrates PJM's standing committees as an example of the structure local governments will want to familiarize themselves with. ERCOT, for example, has established a Renewable Technologies

\section{Box 4 | Financial Considerations for Formal Membership}

Local governments seeking a more active role in their RTO as formal voting members should be aware of the financial impacts related to membership. Depending on their RTO, these may include dues, fees, liability, or other considerations.

In PJM, for example, full members with voting rights pay $\$ 5,000$ in annual membership dues. Other PJM membership levels, such as associate member (offering participation in stakeholder process without voting), ex officio (for state officers or consumer advocates with voting rights), or special member (participation in the Emergency Load Reduction Program without voting rights), have lower annual membership costs and no application fees. Applying for full membership in PJM requires a $\$ 2,000$ application fee and a $\$ 1,500$ risk policy review fee (which covers the administrative cost of assessing the applicant's risk management procedures).

Fees are specific to each RTO and vary. For example, members of the New England Power Pool (NEPOOL), a voluntary association of participants that provides the governing structure for ISO-NE, may also face participant expenses that cover the budget of NEPOOL on top of annual membership fees. These costs are allocated across participant types grouped into end users, alternative resource providers, public-owned entities, transmission/ distribution owners, generation owners, suppliers, and "others." In the past, voting members in the Southwest Power Pool (SPP) had faced large exit fees if they terminated their membership. This fee was based on what was considered that member's share of SPP's long-term financial applications but had effectively become a barrier to membership for smaller stakeholders. The fee was challenged at the FERC level and is currently being revised for non-transmission-owning members to reflect only the direct costs of that member's withdrawal (FERC 2020b).

Joining an RTO can also subject local governments to financial liabilities. In PJM, for example, voting members may be liable for the costs related to the default of a member within the Financial Transmission Rights market that PJM manages. In 2018 the default of GreenHat Energy LLC led to $\$ 160$ million in losses for PJM, a portion of which were then shared by PJM voting members. While voting members that are considered nonmarket participants are limited to a $\$ 10,000$ liability, the risk of future defaults on this scale can present a material concern for local governments considering membership (FERC 2019). This risk may be reduced in the future, as RTOs have begun to revise their policies in light of this default, and FERC has taken interest in this topic as well. 
Figure 8 | PJM Committee Structure

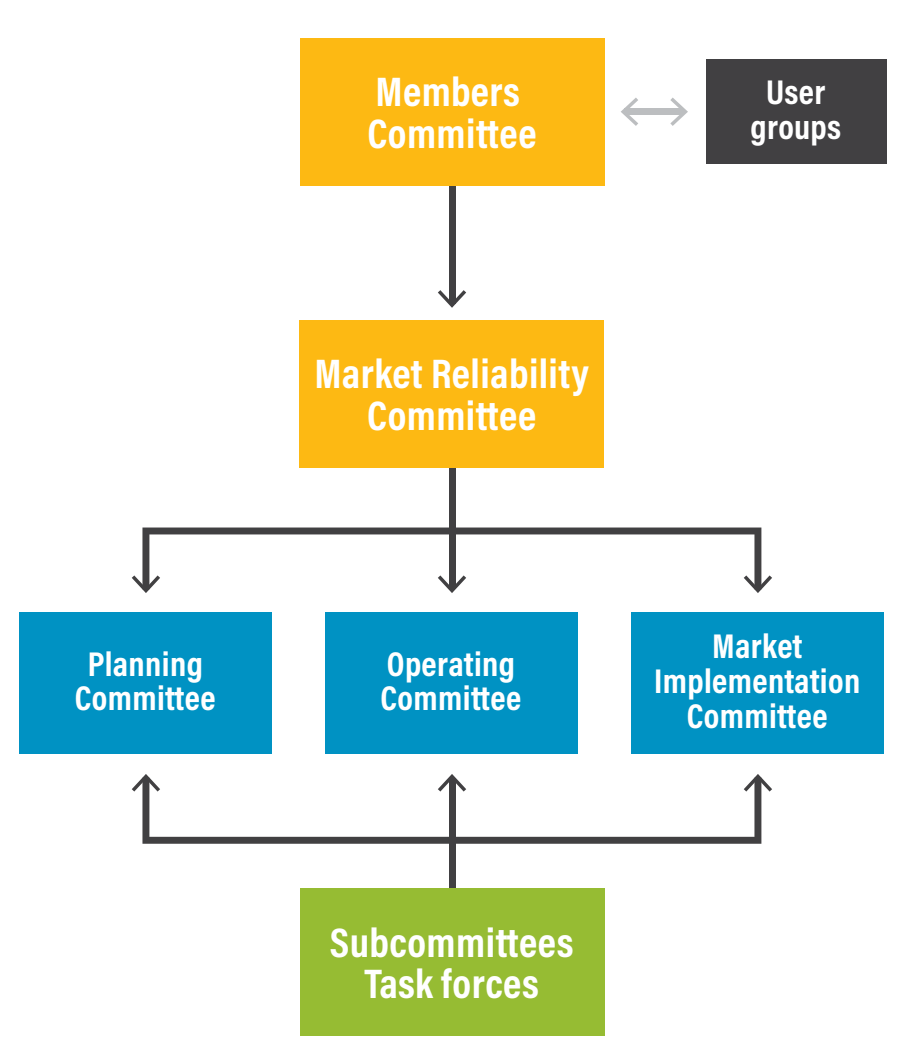

Note: Standing committee structures vary across RTOs. PJM's Members Committee and its Markets and Reliability Committee are senior committees. The Market Implementation Committee, Operating Committee, and Planning Committee are standing committees. Subcommittees that report to standing committees are formed and dissolved on an asneeded basis.

Source: PJM (n.d.).

Working Group as part of its Technical Advisory Committee. This group coordinates and tracks stakeholder efforts to integrate renewable energy, including identifying issues to be resolved, providing training, and holding technical workshops.

\subsubsection{ISSUE IDENTIFICATION AND VOTING IN A STAKEHOLDER PROCESS AS AN RTO MEMBER}

Local governments interested in participating in the stakeholder process for developing market rules should understand how issues are identified, the process for collecting stakeholder input, and voting processes. In many cases voting is weighted by sector, impacting the relative impact of voting for local governments that pursue membership. Box 5 provides more detail. Finally, understanding who holds 205 rights also clarifies where the final say on rules lies (see Section 3.1, where we cover the relationship between states and 205 rights).
The methods for identifying issues and developing proposed solutions through working groups are fairly similar across RTOs. For example, in MISO, new issues are identified by a stakeholder or stakeholder group, submitted to the Steering Committee, then assigned to a specific stakeholder committee. Working through an issue generally begins with education and background, including stakeholder perspectives. Options to address the issue are explored, a straw proposal is introduced, and agreement is reached on a proposal, if possible. Voting members may also raise new issues in meetings.

Raising an issue at PJM requires a problem or opportunity statement, issue charge, and charter. After proposals move through lower committees, they are voted on by the Member Committee, where the five sectors are each given 20 percent of the vote required to approve an action. The Members Committee approves proposals if a supermajority of 75 percent is in favor. While the proposal moves on to the board, the Members Committee holds the Section 205 filing authority. PJM also allows stakeholders to form a user group if five or more members have a shared interest but have been unable to address an issue through the stakeholder process. If established, the user group can propose rule changes directly to the Members Committee and Board of Managers.

The process of voting can differ significantly across RTOs:

PJM: PJM has a two-tiered governance structure composed of members and the independent Board of Managers. The board is PJM's highest governing body. Board members do not have a personal affiliation with or financial stake in any PJM market participant. The Members Committee (MC), the most senior committee in the PJM stakeholder process, is a higher-level committee and votes on all major issues proposed by lower-level committees. Each PJM member gets one vote on the MC but may have additional affiliate votes on lower-level committees. Upon becoming a PJM member, an organization must designate itself in one of the five member sectors, as either a transmission owner, generation owner, other supplier, electric distributor, or end-use customer.

MISO: In MISO, task forces and working groups can use either a straight voting process or a sectorweighted voting process. The Advisory Committee, which is made up of representatives from each sector and approves proposals, uses a weighted voting process based on the number of seats held by that sector. A motion is approved only if it receives a 


\section{Box 5 | Example of Power Dynamics in PJM Voting Processes}

The stakeholder process is a key part of governance, and members have the power to make decisions on market designs, rule changes, and stakeholder engagement, Issues in PJM are generally identified from internal (e.g., PJM staff, members) or external (e.g., FERC, legislators) entities, at high or low levels in the stakeholder hierarchy. The RTO PJM has three types of stakeholder committees: senior standing committees, other voting committees, and nonvoting committees.

Senior standing committees are at the top of the PJM stakeholder hierarchy. They include the Members Committee and the Markets and Reliability Committee. These committees have been structured differently from the rest of the committees, where voting takes place on a sector-weighted basis and each member of this committee gets one vote. For a proposal to pass, a senior standing committee needs a two-thirds supermajority. Other voting committees are at a lower level and only require a simple majority for a proposal to pass. Unlike senior standing committees, all members along with their multiple member affiliates can vote. Proposals that pass the lower-level committees move on to the appropriate higher-level senior committee. Nonvoting committees function as an extension of lower-level voting committees and include subcommittees and nonsenior task forces. These committees pass on recommendations to higher levels and arrive at a consensus on an issue based on support from at least three voting members representing a minimum of two sectors.
A 2017 study of voting power in PJM found that the system of multiple member affiliate voting at the lower level has created a lopsided balance of power. For example, in the period between 2009 and 2016, the Generation Owners and Other Suppliers sectors gained a majority by disproportionately increasing their percentage of total lower-level votes relative to other sectors. Overall, the total PJM membership grew by 78 percent, with a 49 percent increase in voting members, and a 138 percent increase in affiliates. Generation Owners and Other Suppliers accounted for the bulk of total new members. The domination of votes at the lower level gives the sellers more authority over proposal development through member affiliate voting. In addition, members at the higher level have more control over the final vote on proposals through their vote-blocking powers.

The stakeholder process also faces transparency challenges when proposals move from the lower-level committees to the higher-level committees. Higher-level committees aren't given any information about sector voting on a proposal and instead receive only voting percentages. The opacity of this process creates the tendency to pass on proposals that have little to no chance of making it through a sector-weighted vote (Simeone 2017). majority of sector votes. Despite this process, the Advisory Committee has no control over the Board of Directors or MISO, which can file Section 205 proposals with FERC.

ISO-NE: ISO-NE follows a similar process. Proposed market rules changes are presented to the Technical Advisory Committee. If approved by a two-thirds vote, they move on to the Participants Committee for consideration. The Participants Committee is made up of sector representatives, uses weighted voting, and requires two-thirds of votes for approval. Unlike MISO, ISO-NE has the option of an alternate filing pathway in cases of disagreement between the board and advisory committee. If the advisory committee has 60 percent of the votes, it can compel ISO-NE to file an alternate market rule proposal with FERC known as a "jump ball." In such a situation, two proposals are filed by ISO-NE using its Section 205 filing rights.

SPP: SPP has fewer members than MISO and ISO-NE and organizes stakeholder input through quarterly stakeholder prioritization meetings. These meetings are open to both members and nonmembers to raise concerns. Rule changes are developed through organizational groups and task forces, then passed on to the Markets and Operations Policy Committee. This committee passes proposals if the average weighted percent of approval among the sectors reaches 66 percent. The board still retains ultimate approval.

NYISO: NYISO and PJM are similar in that the board of directors and market participants share responsibility for governance. The NYISO governance structure has three committees: Management, Business, and Operating. NYISO also allows for nonvoting entities, which currently make up 31 percent of NYISO members. NYISO follows a weighted voting structure system. The Management Committee approves an action with $5^{8}$ percent of votes in favor. It makes recommendations to the NYISO Board of Directors. The Management Committee and the NYISO Board of Directors have to agree in order to make a Section 205 filing with FERC.

CAISO: CAISO employs an informal stakeholder process for issues that may require a filing at FERC. Issues are ranked based on the most benefit to the market and its stakeholders. These stakeholders 
can now comment on the proposal before CAISO drafts a proposal for the board of governors and again before the board of governors submits it to FERC for approval.

\subsection{Coalitions and Partnerships}

Local governments may be interested in forming partnerships with other groups or in developing a coalition of cities to overcome barriers related to capacity, expertise, and costs. For example, local governments could form a coalition to share the costs of retaining a subject matter expert having deep familiarity with their specific market or the issue at hand. The PJM Cities and Communities Coalition (PJMCCC), for example, retained in its first year an expert consultant who was able to identify PJM committees working on issues relevant to the coalition, provide education on the stakeholder process, and set up direct communications with RTO staff.

In Figure 3 we illustrate that many of the pathways presented in this review lend themselves well to partnership with others or work within a coalition. Coalition building can also strengthen and amplify the voice of local governments. As a group, local governments can share research, align on key messages, and issue joint public comments. This kind of collaboration enables local governments to speak with a unified voice on specific issues so that FERC or their RTO can better understand their concerns and how their clean energy goals are impacted. Even participation in public events, such as FERC technical conferences, could be supported by collaboration. Local governments speaking at these events can identify with a coalition or broader group to lend more credibility to the role of local governments and can collaborate on filing after a technical conference.

While we noted in Figure 3 that joining an RTO as a member and voting is an individual action, this does not block local governments from coordinating with others or within a coalition to develop joint education related to voting matters.

Stakeholders engaging along the pathways outlined as either individuals, collaborators, or a formal coalition should understand how other stakeholder groups are currently engaging. This knowledge helps them understand dialogues already underway, how their messages align or diverge, and who potential partners might be. For this reason, we provide an introduction to how other groups currently engage along these pathways in Section 3. Examining which stakeholder coalitions exist and the issues they are engaging on is a good place for new stakeholders to get up to speed on various issues and identify related educational materials and studies local governments can learn from.

\subsection{Choosing Pathways}

These pathways described above are not mutually exclusive, and local governments may develop strategies that use a blend of approaches, depending on the engagement opportunities available in their specific RTO. For example, local governments may decide to use formal engagement on issues that have the biggest impact on their goals and less formal pathways for issues that do not directly impact goals. Local governments could decide to use pathways with tailored messages, such as using formal comment or direct engagement to share their unique view directly with their RTO while also using public comment to reach a broader audience and catalyze others to take action and/ or spark new partnerships with other stakeholders that could maximize the impact of future engagements.

In addition, pathways for engaging will depend on the issues the city is interested in and how those issues are currently being addressed at the RTO level. For example, if a local government is specifically interested in how hybrid resources (such as solar-plus-storage) participate in wholesale markets and their RTO has a working group currently drafting rules, this could be the right level for engagement. If these rules are the result of a FERC order requiring the RTO to develop them, there could also be value in engaging in the FERC proceeding that will ultimately approve or deny these new rules. In contrast, if the local government is concerned about specific wholesale market barriers that are not currently being addressed, the appropriate pathway could be direct engagement with its RTO and/or partnership with groups that specialize in this topic.

\section{RELEVINT STAKEHOLDERS ENGAGING IN ORGANIZED WHOLESALE MARKETS}

This section describes how other relevant stakeholders have engaged along the pathways described in Section 2. We present this information to provide local governments with more concrete examples of what engagement can look like. We've also selected stakeholders relevant to local governments that may want to model these engagements, build on them, or partner with the groups where interests overlap. 
In general, when new stakeholders consider how their unique voice contributes to dialogues already underway, it is useful for them to understand which other parties are engaging FERC or RTOs and on which topics. Local governments may also want to educate themselves on how utilities, power generators, transmission developers, or others are working on the topics they are interested in engaging on.

\subsection{State Engagement}

Local governments may benefit from understanding how states have engaged with RTOs for a few reasons. Relationships between states and cities in the context of wholesale markets could be important because of the opportunity for these parties to partner. State and local governments may have similar goals and/or limitations. Both represent the interests of their constituents, unlike corporates or advocates, which may cover broader geographies and focus on narrower goals related to their missions. Local governments, at a minimum, may find it useful to understand which topics states are engaging on but could also more actively identify areas where goals align and shape opportunities to collaborate with states. If cities decide to partner with states, they'll need to understand the unique role states play with RTOs. This role differs from that of other stakeholders and can be technical in terms of the official state committees and their role in the RTO stakeholder process. In cases where states and cities differ in their goals, it will still be important for cities to understand how states are impacting issues at the wholesale market level and the avenues for states to engage.

In addition, state efforts to impact RTO governance models or market design can impact the relationship between local governments and their RTO. For example, states within the PJM territory have recently launched formal examinations of pathways for states themselves to manage resource adequacy rather than relying on PJM capacity markets. If successful, cities could be impacted by the changing roles of these parties. Finally, if local governments decide to explore what new formal pathways could be developed to facilitate local government engagement with RTOs (as opposed to being limited to the current pathways described in Section 2), new proposals could draw ideas from the pathways available to states.

State-level entities interact with RTOs along both defined, formal pathways that vary by market, as well as through informal pathways that are open to all state level stakeholders. RTO governance models include formal mechanisms for state engagement that include regional state committees (RSCs), may provide official voting rights as an RTO member or stakeholder, and offer provisions for 205 filing rights. A variety of state-level stakeholders are interested in issues at the wholesale level market, including governors, state energy offices, state legislatures, federal representatives, public utility commissions, and even attorneys general. In recent years, the interaction between state and RTO policies has become a hot topic in multistate RTOs, where parties are more likely to have differing policies related to clean energy.

For multistate RTOs, formal engagement is managed through RSCs, which are funded by the RTO tariffs. For ISO-NE, the RSC is the New England States Committee on Electricity (NESCOE). Table 2 provides an introduction to the RSC in each market. Membership can be focused on state regulators or be broader, as in the case of the OMS membership. Appendix B provides links for local govern-

Table 2 | Multistate RTO Regional State Committees

\section{RTO REGIONAL STATE COMMITTEE \\ COMPOSITION AND ENGAGEMENT LEVEL}

ISO-NE New England States Committee on Electricity (NESCOE)

PJM Organization of PJM States Inc. (OPSI)

MISO Organization of MISO States (OMS)

SPP Regional State Committee (RSC) able to propose market rules.
NESCOE represents the interests of governors in the New England region and focuses on resource adequacy as well as system planning and expansion. The RSC is involved in stakeholder processes and is

OPSI represents state utility regulators, including the Public Service Commission of the District of Columbia. OPSI members can attend stakeholder meetings and have one annual meeting with the board.

OMS is made up of a mix of regulators, advocates, and state legal councils. OMS has seven different working groups on specific topics to provide comments on MISO issues and works collaboratively with the RTO.

The RSC is composed of representatives from each state utility regulator in SPP and participates in committees, working groups, and task forces. 
ments to explore the websites of these groups further and learn more about their structure and activities. The newly established EIM has a governance structure where the Body of State Regulators, with a regulator representative from each state, periodically meets with the EIM Governing Body. The SPP bylaws also outline specific issues over which the RSC has primary responsibility, including resource adequacy and certain elements of transmission planning.

RSCs have been active through both public comment and direct work with RTOs to address clean energy barriers. Examples of public statements from OPSI include letters to the PJM Board of Directors, such as a 2021 letter outlining the RSC's concerns and recommendations for the evolution of market design (OPSI 2021), and expert reports, such as OPSI's recent review of the role of states in relation to PJM (McCabe et al. 2019). RSCs can also have more direct impact on specific rules or broader policy issues through collaboration with RTOs. Box 6 provides a longer example of an initiative in which NESCOE was able to play an active role. RSCs also play an active role in filing comments in FERC proceedings on behalf of the state representatives. Many of these comments can be found listed by year on the RSC websites and cover a wide range of topics, including transmission and market rule issues. While RSCs are important organizing bodies for states in each RTO, they do not define all state action. States may not always choose to join public comments or may engage in their own public comments.

Voting as members on decision-making is another mechanism for states to impact RTO rule development. In ISO-NE, MISO, and SPP, states are considered members and play a role voting within the stakeholder process. ${ }^{11}$ In PJM, states have declined to become voting members but have explored ways to increase states' influence over PJM decision-making (McCabe et. al. 2019).

In single-state RTOs, RSCs are not needed, although state agencies still play a role in decision-making. In CAISO, for example, the California governor appoints all the members of the RTO's board. While the RTO does not use a member and committee stakeholder structure, stakeholders can bring issues to CAISO and comment on proposed solutions. The state has planning functions split across the California Energy Commission, the California Public Utilities Commission, and CAISO, which collaborate often. Similarly, NYISO works in partnership with the New York State Energy Research and Development Authority and the New York Public Service Commission. Both the Public
Box 6 | ISO-NE's Integrating Markets and Public Policy Initiative

In 2016 the New England Power Pool (NEPOOL) launched a stakeholder engagement process known as the Wholesale Markets and State Public Policy Initiative, or Integrating Markets and Public Policy (IMAPP). IMAPP's goal was to integrate states' policy-related requirements into wholesale electricity market design and to explore potential changes that could be implemented to advance state public policy objectives in New England. IMAPP participants sought to execute states' public policy goals at the lowest reasonable cost without diminishing the benefits of competitive organized markets or amplifying the cost to consumers.

Throughout the IMAPP process, participants held nine meetings and developed 17 various proposals on topics ranging from carbon pricing to new resource investment. Through this effort, NEPO0L participants were able to work with states individually and through the New England States Committee on Electricity for all parties to better understand the proposals and concerns. Working together, the IMAPP participants issued a conceptual proposal in 2017 intended to accommodate state public policy objectives while addressing capacity market pricing concerns. Shortly thereafter, the working group shifted its attention to evaluating the solution put forward by ISO-NE, the Competitive Auctions with Sponsored Policy Resources (Lombardi 2019).

Utility Commission of Texas and the Texas legislature have oversight of ERCOT, whereas other organized markets are regulated by FERC.

The right to pursue a 205 filing in matters related to energy, ancillary services, or capacity markets ${ }^{12}$ varies across RTOs. For example, MISO and SPP Section 205 rights are shared across the RTO, the transmission owners, and the RSC for specific topics and not others. In CAISO, ISO-NE, and NYISO, however, 205 rights are given to either the RTO or one of its governing committees, not states. Any stakeholder can file 206, however, using the higher burden of proof, leaving open an avenue for state action.

\subsection{Consumer Advocates, Environmental Groups, and Public Interest Groups}

Local governments can also learn from the experiences of consumer advocates, environmental groups, and public interest groups, particularly in cases where these groups address barriers to renewable energy at the wholesale market level. Like states, these parties often have a long-standing history within their RTOs and formalized pathways to engage as stakeholders. Many RTOs have established stakeholder groups for these parties. 
Consumer advocates in MISO, for example, have a stakeholder group although they are not considered MISO members. This group includes coalitions and alliances, state offices of the attorney general, state citizen utility boards, and others. PJM, in contrast, does not have a stakeholder group for consumer advocates, but the latter have organized themselves into the Consumer Advocates of PJM States (CAPS), with funding from the PJM tariff, and are able to jointly hire subject matter experts to analyze specific issues of interest, such as peak load shaving or resource adequacy. CAPS has also been successful in direct engagement with PJM leadership. For example, CAPS representatives were able to discuss their proposal to fund CAPS through a new charge on PJM's tariff directly with PJM's then-CEO, Andrew Ott.

Several notable environmental groups engage in different ways. For example, the Clean Grid Alliance has pursued official membership in MISO to advance renewable development, which allows it access to the Advisory Committee and the Planning Advisory Committee. It also monitors MISO's subcommittees and working groups for issues that could affect renewable development, and it has published blogs on key issues facing renewables, reaching a broad audience.

Similarly, the Wind Solar Alliance is involved in addressing barriers in MISO and PJM that could slow wind and solar development by not properly valuing the benefits of these energy sources. The alliance has developed broad, public educational resources on how PJM can become "more customer focused and clean" (Goggin et al. 2018), highlighted the benefits of wind and solar in ERCOT, and provided education about the impact of transmission planning on clean energy development.

The Public Interest and Environmental Organizations Users Group (PIEOUG) is an example of a public interest group that is organized according to a requirement in its RTO operating agreement. The PIEOUG, a part of PJM's Members Committee (MC), reviews and decides on all major changes related to competition, reliability, and fairness. The group provides an open forum for policy discussion, which serves as a pathway to solicit input from environmental and public interest communities. Membership in the PIEOUG is open to organizations that are either consumer advocates or environmental and public interest organizations. PJM also has a provision enabling organizations not eligible for membership to be involved in its stakeholder process.
Other environmental groups collaborate on renewable development barriers in organized wholesale markets through the Sustainable FERC Project, housed within the Natural Resources Defense Council. This project advocates for clean energy and carbon-free systems at both the FERC and RTO levels. Through the platform, nongovernmental organizations collaborate to challenge or support issues at the FERC level, engage in RTO-level rules, provide broad educational resources, develop blogs on important issues, reach broad audiences by sharing resources through informal pathways such as Twitter, and collaborate with stakeholders such as local governments.

In addition to environmental groups and consumer advocates, the business community has also played a role in addressing barriers to renewable energy at the wholesale market level. A key example is the Sustainable Growth Coalition, a partnership of nearly 30 businesses, including utilities, corporates, and nonprofits. Recently, the coalition underscored the need for transmission investments by unveiling its Transmission Guiding Principles to help advance the Midwest's competitiveness and meet customer needs.

\subsection{Corporate Engagement}

Large corporate entities with renewable energy purchasing goals, which often use regulatory engagement to further their efforts to decarbonize the grid, are also increasingly interested in issues at the wholesale market level. For some corporate customers, alliances and coalitions have been useful for providing education on wholesale market issues and avenues to engage through regulatory filings and direct communications. A limited number of large corporates have joined RTOs as voting members, including Google, Walmart, Tesla, and 3M. Local interest from corporates can also drive targeted engagement in issues at the wholesale market level. Corporate wholesale market engagement is a useful example and a potential partnership pathway considering the experience and resources corporates have in this area. Corporate and city partnership on wholesale market issues could also allow these parties to drive greater regional decarbonization and a community focus. The Sustainable Growth Coalition (SGC), discussed below, originally launched as the Minnesota Sustainable Growth Coalition. It has provided a local focus and the ability to examine the community impact of energy development in the region, including on equity issues. 
One example of education through collaboration is the Renewable Energy Buyers Alliance (REBA). Bringing together large clean-energy buyers, energy providers, and service providers, REBA provides members with education and opportunities for collaboration that further corporate procurement of renewable energy and broad decarbonization. In recent analysis of policies that increase access to renewable energy and decrease costs of procurement, REBA found that organized wholesale markets increased customer options while reducing costs and facilitating renewable energy integration (REBA 2020). REBA also provides education for its members on wholesale market issues that may impact members within their markets.

Similarly, Advanced Energy Economy (AEE) is a businessled coalition of leading advanced energy purchasers, such as Google, Facebook, and Target. They convene an Advanced Energy Buyers group to coordinate on policy issues that impact their goals and work to remove barriers to advanced clean energy technologies within wholesale markets. This group has coordinated on several issues and filed comments in FERC dockets addressing transmission incentives, recent proposed changes to PJM's capacity market, participation of distributed energy resources in wholesale markets, and enhanced grid resilience.

A recent issue that is driving even more corporate interest in wholesale markets is the need to develop transmission to connect renewables to load-centers more rapidly. In 2019 the Wind Solar Alliance released a report highlighting the disconnect between corporate demand for renewable projects and RTO transmission planning, ultimately urging corporates to become more involved through advocacy groups or by joining RTOs as voting members. With transmission planning time frames averaging 10 years and time frames for building new renewable projects around 2 years, underestimating demand can create significant barriers (Pfeifenberger 2019; Caspary 2021). This disconnect has been felt most directly in the MISO planning region, where at least 5,000 megawatts of new renewable projects have been unable to come online due to transmission barriers (CGA 2019). Corporates have responded to this report: in 2020 the Sustainable Growth Coalition communicated its energy goals directly to MISO in a joint letter. The coalition has also developed guiding principles for transmission planning in the MISO region, underscoring the benefits of removing transmission barriers that threaten corporate sustainability goals. Notably, the SGC includes not only business partners but also two utilities, Xcel Energy and Great River Energy, illustrating the possibility for large customers to partner with utilities on issues at the wholesale market level.

\subsection{Local Government Engagement}

\subsubsection{Local government participation in pathways}

While the role of local governments in engaging in RTOlevel issues is currently limited, important examples of engagement exist. For some cities, their role as municipal utilities, community choice aggregation entities that in some cases are transmission owners, has already brought them into RTO governance structures. For others, key issues have led to individual action through both formal and informal comments. Finally, some cities are building coalitions to organize and strengthen city engagement.

In MISO, for example, the municipal utilities in the cities of Benton, Arkansas; Cleveland, Ohio; Henderson, Kentucky; Lansing, Michigan; and Rochester, New York, are already formal MISO members within the Municipal and Cooperative Electric Utilities and TransmissionDependent Utilities sector. The New Orleans City Council, in contrast, is part of the State Regulatory Authorities special interest group sector, bodies that are not MISO members but are granted voting rights. This role was tied to a 2013 decision for Entergy New Orleans to join MISO, which required approval from the council as Entergy New Orleans was previously under its jurisdiction. The council approved the move after a cost-benefit analysis. Further study found that after the first three years of being part of MISO, the utility delivered $\$ 36$ million in benefits to customers stemming from more efficient dispatch of power on the transmission grid and reduced operating reserves (Cavell 2017).

For other local governments, key issues have piqued city interest and led to filed comments at FERC. In 2020, for example, FERC received a petition from the New England Ratepayers Association requesting that the commission issue a declaratory order announcing its jurisdiction over net-metering issues. The City of Keene, New Hampshire; and Broward County, Miami-Dade County, and Palm Beach County, Florida, all submitted comments in the related FERC Docket EL20-42-00o. The city and counties cited the need to uphold state jurisdiction as well as the threat such a decision would constitute to distributed solar programs. Similarly, the City of Farmington, New Mexico, petitioned to intervene as a municipal utility, and New York City petitioned to intervene as "the largest electricity 
consumer in New York City and in a representative capacity on behalf of its residential, commercial, institutional, and industrial electricity consumers."

\subsubsection{PJMCCC and local government coalitions}

The new PJM Cities and Communities Coalition is the first coalition of cities and communities organized specifically to address wholesale market issues. In 2019, 18 cities with ambitious energy goals in the PJM territory began to recognize the lack of city engagement on wholesale market issues despite the large impact PJM issues could have on the regional grid mix. In response, they explored collaborative action as a way to overcome engagement barriers, such as the high level of market expertise needed to engage, inadequate educational resources for local governments, and limited capacity for city staff to engage on their own. After a year of grant-funded coalition building, cities remarked that they had learned that having a clear structure facilitated shared work, that partnerships and relationships are of high value for cities to have impact, and that the impact of PJM policy on cities is significant but not widely understood. PJMCCC is now a fully organized coalition, guided by a shared charter that members are currently in the process of adopting. Box 7 highlights the mission and scope of work the cities have defined through this charter.

The coalition's structure, format for providing member education, and member expectations are also outlined in its charter. To allow cities to commit to a level of participation that suits their capacity, PJMCCC membership comprises three tiers: the Dual Member Cities Tier, the Participating Cities Tier, and the Observing Cities Tier. The Dual Member Cities Tier recognizes cities that are Participating Cities in PJMCCC as well as official members of PJM, ${ }^{13}$ allowing them to vote within PJM's governance structure and influence policy. Members of the Participating Cities Tier commit to serving as active partners in PJMCCC and drive the coalition in developing or executing the shared agenda. The Observing Cities Tier is composed of cities that opt to play a nonactive role but have access to coalition education materials and the ability to join public comment. Member education includes monthly all-member calls, webinars, and email-based policy updates. The PJMCCC Steering Committee strategically drives the coalition, while the Policy Committee develops and advances public policy positions. Using this structure, PJMCCC has engaged at the public, FERC, and RTO levels and continues to expand its engagement along new pathways.
PJMCCC has used public comment and continues to explore ways to increase its local leadership on PJM issues. In 2019, as PJM's search for a new CEO was underway, the coalition used its collective voice to develop a public letter to the PJM Board of Directors. This letter urged the Board of Directors to prioritize a new CEO who could move PJM to a clean energy future, joining a chorus of similar messages from other stakeholders, including environmental advocates and state attorneys general (PJM 2019). In 2020, the coalition also developed its "PJMCCC Policy Statement on the Benefits of Reducing Barriers to Energy Storage in the PJM Region.” The statement called for updated market rules and operational changes within the PJM wholesale market that support the deployment of energy storage technologies in light of proposed changes to how the capacity contributions of storage are calculated. The statement emphasized that reducing barriers to storage technology aligns with member cities' goals for renewable energy integration, resilience, and equity. ${ }^{14}$ Finally, the coalition also used outside subject matter support to provide members with education and analysis of what was then still a proposed expansion of the Minimum Offer Price Rule ${ }^{15}$ and the impact it could have on planned city renewable energy purchases. As both large electricity users and public entities, the cities continue to track this rule, which according to estimates could cost consumers $\$ 1$ billion to $\$ 2.6$ billion annually and reduce renewable energy development. The coalition also has begun to consider what new research and education will be needed on PJM topics, how to share education with a wider set of cities and communities, and how to connect efforts with local public institutions that have similar goals.

PJMCCC has also begun to engage at the FERC level, prioritizing the most accessible, informal actions, and is considering more formal engagement in the future. As an educational offering, PJMCCC highlights public, FERChosted events for members, increasing their participation in this outreach and sharing what attending members learned with the broader group. For example, in 2020 PJMCCC members attended the FERC General Session and Carbon Pricing Conference and discussed the topics covered. The coalition has also collaborated with informal partners to draw connections between PJMCCC public comment and FERC filings. The coalition's storage policy statement was cited by comments public interest organizations have filed on the PJM's ELCC proposal. As PJMCCC builds its capacity for public comment, it plans to file direct comments before FERC on relevant topics, requiring deeper education on relevant proceedings and the ability to meet specific filing deadlines. 


\section{Box 7 | Elements of the Charter of the PJM Cities and Communities Coalition}

The following text from the coalition's charter outlines the opportunities these cities have identified and used to organize their mission and scope of work:

\begin{abstract}
Mission: The PJM Cities and Communities Coalition has been launched to coordinate the efforts of cities in the PJM territory that are interested in removing and preventing barriers to decarbonization solutions in their regional wholesale electricity market. The Coalition provides a platform for members to educate and build capacity on these issues, form partnerships to collaborate with similarly aligned organizations, and create opportunities for members to work collectively to drive decarbonization within the PJM region.
\end{abstract}

Cities have an additional unique lever as both large electricity users and political entities. Mayors and other city leadership can use their platforms to elevate PJM issues and bring more attention to the climate impacts of decision-making.

Scope: The Coalition is focused on driving decarbonization at the wholesale market level which may require engagement with the Federal Energy Regulatory Commission (FERC), PJM, utilities and others.

\section{PJM Policy and Regulation}

The Coalition specifically supports PJM action that: 1) Preserves

policies that open markets to low carbon energy resources and solutions; 2) Ensures organizational and governance reforms so that cities and other end users can equitably weigh in on key decisions affecting their constituencies; and 3) Focuses on maintaining access, transparency, and accountability in PJM governance and operations.

\section{Aligning Goals and Planning Regionally}

The Coalition cities are dedicated to pursuing solutions to climate change, reducing carbon emissions, and removing barriers to decarbonization solutions in their regional wholesale electricity market. Many cities in PJM have set individual climate goals and are taking steps to reduce local greenhouse gas emissions and see the need to build on this leadership. The cities will support efforts to align decarbonization goals with the various levels of planning within the PJM region, including actions at the Regional Transmission Organization (RTO), state and utility level.

\section{Low Carbon Solutions}

The coalition will support decarbonization solutions which may include but are not limited to: Renewable Energy; Demand Side Management; Energy Efficiency; Energy Storage Applications; Beneficial Electrification such as Electric Vehicles; and Carbon Pricing.

Source: www.pjmccc.org.

At the RTO level, PJMCCC has pursued direct engagement with PJM staff as a key strategy for building productive relationships and sharing local government and community concerns with PJM leaders. RTO staff working with government have traditionally focused on the state level. One-on-one conversations with PJMCCC have allowed the coalition to introduce a new perspective on issues, with a goal of building PJM's capacity to work with them as a new stakeholder group. Discussions have been facilitated at a high level between PJM's External Affairs and PJMCCC's Steering Committee and at a more granular level between PJMCCC's Policy Committee and staff working on related market issues. The flexibility provided by informal conversations has made direct engagement a useful starting point for the coalition at the RTO level. These discussions can be scheduled according to the availability of local government and RTO staff and can address a wide range of topics in whatever depth is most appropriate at the time. While the coalition plans to become more active in PJM stakeholder outreach, those interactions would target specific outcomes and involve the broad range of PJM stakeholder groups.
Finally, the local governments have engaged with several partners active in PJM issues to educate its members and identify opportunities to collaborate on important issues.

\section{CONCLUSION}

As local governments work toward achieving their renewable and clean energy goals, expanding their regulatory engagement to include issues at the wholesale market level could help remove barriers to their own purchases as well as drive regional clean energy development. Wholesale markets are a key tool for increasing renewable energy purchasing and integration but are also evolving to meet the changing needs of the industry. While each RTO differs, all have governance models that allow for stakeholder involvement.

Interested local governments will need to evaluate the feasibility, resource requirements, and potential impact of different engagement approaches in order to determine the pathways most appropriate for them. Public comment and direct engagement with RTOs can allow local governments to engage more quickly and on their own time 
frames but may not be as impactful as other avenues. For local governments considering how to engage, the status of a specific issue and how it is being addressed might drive engagement decisions as much as cost and impact. Engagement at the FERC level and in RTO stakeholder processes can allow local governments to add their comments and unique voice to the public record but may entail significant costs and time investment. Joining an RTO as a formal voting member might give local governments the most direct impact on market rule development, but this approach is the most expensive and comes with the highest liability. Finally, the pathways presented are not mutually exclusive, and stakeholders generally engage along several pathways at once, often in collaboration with others.

Local governments can learn from the existing engagement of states, consumer advocates, environmental groups, public interest groups, and corporates when considering engagement and consider how their goals and approaches might overlap. The emergence of the PJM Cities and Communities Coalition is an important example of how coalition building can distribute the work of engaging and enable members to have a stronger voice. As PJMCCC matures and other local governments become involved in similar efforts, more lessons about the effort pathways require versus their value will emerge, as will understanding of opportunities for partnerships. For example, local governments' ability to engage with their utility on wholesale market-level issues was not explored as a pathway in this paper but could be in the future.
Local governments interested in engaging can treat this report as an introduction to engagement in terms of why to engage, how to engage, and which other stakeholders may be active in their area. Appendix B provides some entry-level resources for understanding wholesale markets as well as key links to important resources specific to their RTO. Local governments considering the value of incorporating wholesale market-level engagement into their regulatory and engagement strategy can use this basic education to begin exploring the specific barriers to clean energy in their markets and begin connecting with other stakeholders to understand how these barriers are currently being addressed. 


\section{APPENDIX A: LOCAL GOVERNMENT \\ PURCHASES OF RENEWABLE ENERGY}

\section{Project Structures}

As much as 90 percent of renewable energy deals used by local governments are structured as off-site power purchase agreements

(PPAs). In off-site PPAs local governments become "off-takers" for renewable power by contracting with developers to take ownership for a specific amount of power that is then delivered onto the grid near the customer. Local governments also utilize other project types based on purchasing options and their goals. Other project structures include off-site virtual PPAs, similar to those used most often by corporate customers, which do not require local governments to take physical ownership of the renewable energy or to purchase power within their own market. In an off-site virtual PPA, purchased power is sold into the local market and the PPA contract acts only as a financial instrument. The local government either pays or receives the difference between what the power earns in the market and the price the local government agreed to in its contract. Other project structures used are community solar and on-site deals, which are often helpful in achieving other city goals related to local impact and can cost less than PPAs. Local governments can also partner with their utilities to develop green tariffs that provide renewables through long-term contracts through their utility.

For more information on how local governments are leading on renewable energy procurement, please see https://cityrenewables.org/. This resource provides information on state options for renewable procurement, procurement methods, case studies, and purchasing data.

Figure A1 | Transactions by Size and Electric Power Market

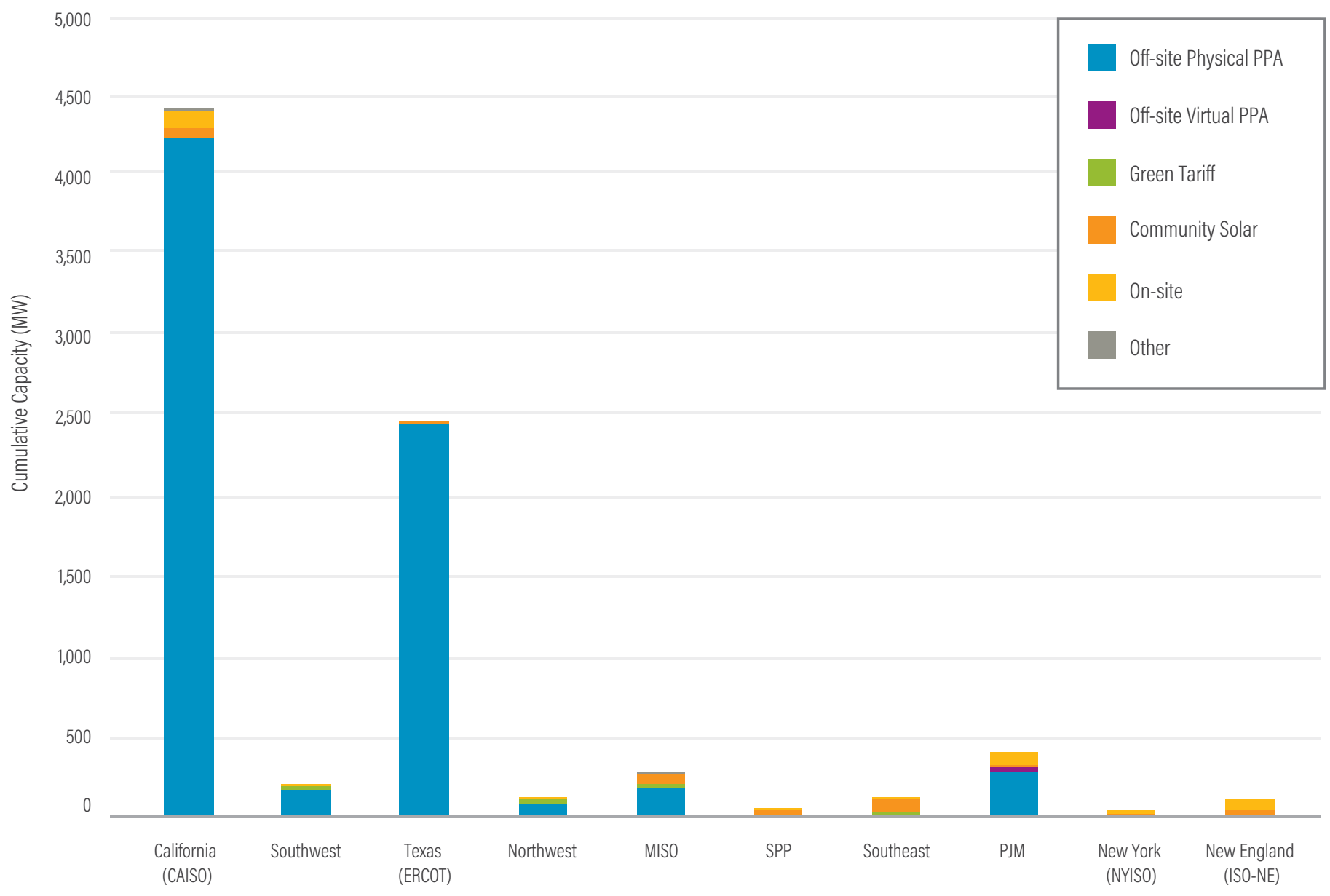




\section{APPENDIX B: SUGGESTED INTRODUCTORY PRIMERS AND OTHER RESOURCES}

The following links provide introductory resources that detail wholesale electricity markets. Additionally, resources regarding RT0-specific materials such as operation agreements, tariffs, and regional RTO governance information are highlighted below.

\section{General Resources}

- "Competitive Electricity Market Regulation in the United States: A Primer" (2016): https://www.nrel.gov/docs/fyl70sti/67106.pdf

- "Wholesale Electricity Markets and Regional Transmission Organizations": https://www.publicpower.org/policy/wholesaleelectricity-markets-and-regional-transmission-organizations

- "Wholesale Electricity Markets and Regional Transmission Organizations" (January 2021): https://www.publicpower.org/system/files/documents/ January\%202021\%20-\%20Wholesale\%20Electricity\%20Markets.pdf

- "Organized Wholesale Markets and Corporate Advanced Energy Procurement: How Competitive Markets Help Commercial and Industrial Buyers Meet Their Sustainability Goals, and How They Can Be Improved" (2021): https://info.aee.net/hubfs/AEE_AEBG\%20-\%20 WholesaleMkts_1.19.21.pdf

- "Solar Energy: SolSmart's Toolkit for Local Governments-Utility Engagement": https://solsmart.org/solar-energy-a-toolkit-for-localgovernments/utility-engagement/

- "Explainer: Demystifying U.S. Electricity Markets and Their Role in Clean Energy Expansion" (2019): https://www.wri.org/blog/2019/10/ insider-demystifying-us-electricity-markets-and-their-role-clean-energyexpansion

- "Explainer: How Some U.S. Cities Are Working to Align Energy Markets with Their Clean Energy Goals" (2020): https://www.wri.org/ blog/2020/10/united-states-cities-energy-markets-pjm-ccc

- Sustainable FERC Project: https://sustainableferc.org/

\section{FERC Resources}

- FERC Energy Primer (2020): https://www.ferc.gov/sites/default/ files/2020-06/energy-primer-2020.pdf

- "A Primer for Understanding FERC Order 2222" (2020): https:// cpowerenergymanagement.com/a-primer-for-understanding-fercorder-2222/

- "Power Sales and Markets" (2020): https://www.ferc.gov/industries-data/ electric/power-sales-and-markets

- "Formal Complaint Procedures" (2020): https://ferc.gov/enforcementlegal/legal/complaints/formal-complaints

- "Template for Petition for Declaratory Order" (2020): https://www.ferc. gov/sites/default/files/2020-06/declar-order-template.doc

\section{RTO/ISO-Specific Resources}

CAIS0: http://www.caiso.com/Pages/default.aspx

- "Navigating CAISO": https://sustainableferc.org/navigating-caiso/

- "Fifth Replacement FERC Electric Tariff" (2020): http://www.caiso.com/ Documents/Conformed-Tariff-as-0f-Dec1-2020.pdf

- Board of Governors: http://www.caiso.com/informed/Pages/ BoardCommittees/Default.aspx

- "Recurring Stakeholder Processes": http://www.caiso.com/informed/ Pages/RecurringStakeholderProcesses.aspx

ISO-NE: https://wwwiso-ne.com/

- "Navigating ISO-NE": https://sustainablefercorg/navigating-iso-ne/

- "Participants Agreement": https://www.iso-ne.com/static-assets/ documents/2015/10/parts_agree.pdf

- "Memorandum of Understanding" (2007): https://wwwiso-ne.com/staticassets/documents/regulatory/part_agree/mou_final.pdf

- "Transmission, Markets, and Services Tariff": https://wwwiso-ne.com/ participate/rules-procedures/tariff/

- "Board of Directors:" https://wwwiso-ne.com/about/corporategovernance/board

- New England States Committee on Electricity: http://nescoe.com/

- "Governance Structure:" http://nescoe.com/wp-content/uploads/2021/02/ ISO-RTOGovernanceStructureandPractices_19Feb2021.pdf

MISO: https://www.misoenergy.org/

- "Navigating MISO": https://sustainableferc.org/navigating-miso/

- "Tariff": https://www.misoenergy.org/legal/tariff/

- "Stakeholder Governance Guide" (2020): https://cdn.misoenergy.org/ Stakeholder\%20Governance\%20Guide105455.pdf

- "Board of Directors": https://www.misoenergy.org/about/board-ofdirectors-and-leadership/operational-leadership/

- Organization of MISO States: https://www.misostates.org/

- "Regional State Committee": https://spp.org/stakeholder-groups/ organizational-groups/regional-state-committee/ 
NYISO: https://www.nyiso.com/

- "Navigating NYISO": https://sustainableferc.org/navigating-nyiso/

- "Market Administration and Control Area Services Tariff" (agreement) (2021): https://nyisoviewer,etariff.biz/ViewerDocLibrary/MasterTariffs/9Fu IITariffNYISOMST.pdf

- "NYISO Shared Governance" (2018): https://www.nyiso.com/ documents/20142/1408883/Introduction-to-the-NYISO.pdf/0910588e41de-5c38-380f-23c176792bd4

- "Who We Are" (Board of Directors and leadership): https://www.nyiso. com/who-we-are

PJM: https://www.pjm.com/

- "Navigating PJM": https://sustainableferc.org/navigating-pjm/

- "Operating Agreement of PJM Interconnection" (effective July 14, 2011): https://www.pjm.com/directory/merged-tariffs/oa.pdf

- PJM Stakeholder Process (2019): https://www.pjm.com/ /media/ documents/manuals/m34.ashx

- "PJM Open Access Transmission Tariff" (agreement) (effective September 17, 2020): https://www.pjm.com/directory/merged-tariffs/oatt.pdf

- Organization of PJM States Inc.: https://opsi.us/

- "Governing Documents": https://www.pjm.com/library/governingdocuments.aspx

- "PJM Board of Managers": https://pjm.com/about-pjm/who-we-are/ pjm-board.aspx\#: ; 'text=\%20PJM\%20Board\%20of\%20Managers\%20 \%201\%20Ake,system\%20planning\%20and\%20operation.\%20Most\%20 recently,...\%20More

SPP: https://spp.org/

- Navigating SPP: https://sustainableferc.org/rto-backgrounders/ navigating-spp/

- SPP Governing Documents Tariff: https://spp.org/documents/13272/ current\%20bylaws\%20and\%20membership\%20agreement\%20tariff.pdf

- SPP Governance: https://spp.org/governance/

- SPP Board of Directors: https://www.spp.org/stakeholder-groups/ organizational-groups/board-of-directorsmembers-committee/

- SPP's Regional States Committee: https://www.spp.org/stakeholdergroups/organizational-groups/regional-state-committee/
ERCOT: http://www.ercot.com/

- ERCOT Stakeholder Process: http://www.ercot.com/content/wcm/key_ documents_lists/214083/05._Stakeholder_Process_Overview_011221. PPTX

- ERCOT Governance: http://www.ercot.com/about/governance

- Public Utility Commission of Texas: https://www.puc.texas.gov/

- Nodal Operating Guide: http://www.ercot.com/mktrules/guides/ noperating

- ERCOT Board of Directors (March 2021): http://www.ercot.com/about/ governance/directors 


\begin{tabular}{|c|c|c|c|}
\hline AEE & Advanced Energy Economy & NESCOE & New England States Committee on Electricity \\
\hline CAISO & California Independent System Operator & NYISO & New York Independent System Operator \\
\hline CAPS & Consumer Advocates of PJM States & OMS & Organization of MISO States \\
\hline DER & distributed energy resource & OPSI & Organization of PJM States Inc. \\
\hline EIM & energy imbalance market & PIEOUG & Public Interest and Environmental Organizations Users Group \\
\hline ELCC & effective load carrying capacity & PJMCCC & PJM (originally Pennsylvania, New Jersey, and Maryland) \\
\hline ERCOT & Electric Reliability Council of Texas & & Cities and Communities Coalition \\
\hline FERC & Federal Energy Regulatory Commission & PPA & power purchase agreement \\
\hline FPA & Federal Power Act & REBA & Renewable Energy Buyers Alliance \\
\hline IRS & Intermittent Resources Subcommittee & RGGI & Regional Greenhouse Gas Initiative \\
\hline ISO & independent system operator & RSC & regional state committee \\
\hline ISO-NE & Independent System Operator-New England ${ }^{16}$ & RTO & regional transmission organization \\
\hline MISO & Midcontinent Independent System Operator & SGC & $\begin{array}{l}\text { Sustainable Growth Coalition (formerly Minnesota } \\
\text { Sustainable Growth Coalition) }\end{array}$ \\
\hline & & SPP & Southwest Power Pool \\
\hline
\end{tabular}

\section{GLOSSARY}

ancillary services market

California Energy Commission

California Independent System Operator (CAISO)

\section{California Public Utilities} Commission

capacity market

compliance filing

day-ahead energy market
A wholesale market for resources that can come online quickly and balance the system as it moves electricity. Ancillary services vary by market but typically include reserves and regulation products.

California's primary energy policy and planning agency.

Nonprofit public benefit corporation that operates the majority of California's wholesale power grid.

Agency that regulates privately owned public utilities in California, including electric power, telecommunications, natural gas, and water companies.

An auction where generators set their bid price that is equal to the cost of keeping their plant available to operate when needed. Bids are arranged in ascending order, and once the bids reach the required quantity that all the retailers collectively must acquire in order to adequately meet expected demand (peak demand plus a reserve), the market "clears." Generators that "clear" this market at the bid price where supply meets demand receive the same clearing price. This clearing price is determined by the bid price of the last generator used to meet demand.

Pending companies or persons under the jurisdiction of the commission are required to adhere to orders, permits, or license provisions. A filing with the commission stating that these requirements have been met is called a compliance filing.

Forward energy market to buy and sell electricity to the next day. Hourly locational marginal prices are calculated for the next day, based on supply, demand, and scheduled transactions between buyers and sellers of energy. 
GLOSSARY (CONT.)

energy market

\section{ex parte rules}

interconnection

member affiliate

organized wholesale markets

\section{PJM}

public utilities commission

real-time energy market

regional transmission organization

regulation (ancillary services)

reserve margin

reserves (ancillary services)

resource adequacy

205 Filing Right

206 Filing Right

vote dilution
Auction where electric suppliers offer to sell the electricity generated for a particular bid price, while load-serving entities (the demand side) bid for that electricity in order to meet their customers' energy demand on a day-to-day basis. Supply-side quantities and bids are ordered in ascending order of offer price. The market "clears" when supply meets demand, and generators receive this market price per megawatt hour of power generated.

Rules barring FERC employees from discussing contested proceedings in off-the-record discussions to avoid unfair advantage among parties. Informal rulemakings that do not have official parties.

Processes of connecting new generation to the transmission system, guided by RTO rules and processes where organized wholesale markets exist.

Company associated with a member parent company within PJM's stakeholder process. Only one member from the related companies may hold voting rights, so many member affiliates can participate in committees but cannot vote.

Purchase and sale of electricity from generators to resellers, along with the ancillary services needed to maintain reliability and power quality at the transmission level. Resellers include electricity utility companies, competitive power providers, and electricity marketers.

PJM Interconnection LLC, a regional transmission organization in the Eastern Interconnection grid operating an electric transmission system in the United States.

Governing body that regulates the rates and services of a public utility, such as an electric utility. Also known as a utilities commission, utility regulatory commission, or public service commission.

Spot market in which electricity is procured for immediate delivery based on locational marginal prices that are calculated at five-minute intervals.

Independent, membership-based, not-for-profit organizations that ensure reliability and optimize supply and demand bids for wholesale electric power. Areas within regional transmission organizations or independent system operators are considered to be organized wholesale markets.

The terms regional transmission organization and independent system operator are often used interchangeably, though there are small differences between them.

Reliability product that corrects unforeseen short-term fluctuations in electricity use and supply that could affect the stability of the power system.

Excess capacity above the amount needed to meet expected peak demand.

Generation resources that can quickly come online within 10-30 minutes in the event of an unexpected loss in generation, such as a downed generator.

Ability of a utility or market to satisfy future customer load, especially during a peak demand period, such as a heat wave or cold snap, while maintaining an acceptable level of reliability.

Filing right of the Federal Power Act requiring that the proposer of a change to "all rates and charges for or in connection with the transmission or sale of electric energy and all rules and regulations affecting or pertaining to such rates and charges" demonstrate why the change is "just and reasonable." (16 U.S.C. § 824d)

Filing right of the Federal Power Act requiring that the proposer of a change to "all rates and charges for or in connection with the transmission or sale of electric energy and all rules and regulations affecting or pertaining to such rates and charges" meet a more stringent standard to demonstrate why the change is "just and unreasonable." (16 U.S.C. $§ 824 e)$

Event where a majority group diminishes the effectiveness of votes from the minority group.

Note: Several definitions have been aligned with the America's City Climate Challenge Renewable Accelerator glossary that local governments may already be familiar with. See https:/l cityrenewables.org/glossary/. 
1 In areas without organized wholesale markets, vertically integrated utilities continue to own generation, transmission, and distribution assets and are the main drivers of resource development in their territory. Where there are organized wholesale markets, utilities are sometimes largely still vertically integrated (CAISO, SPP, MISO) or they may be restructured (ERCOT, ISO-NE, PJM, NYISO). In restructured markets, RTOs and competitive generators may have more impact on generation development than in vertically integrated markets.

2 FERC Orders nos. 888 and 889 introduced the concept of an independent system operator (ISO). Later, in Order 2000, FERC built on this concept by laying out 12 characteristics and functions required to be considered a regional transmission organization (RTO). The roles of ISOs and RTOs are very similar, though RTOs have more responsibility over transmission. The two terms are generally used interchangeably. For simplicity we refer to all organized wholesale markets as RTOs throughout this paper.

3 While virtual PPAs expand access to renewable energy project investment, they can be less impactful than physical PPAs as they only provide renewable energy credits and not the physical delivery of renewable energy. As a primarily financial agreement, the developer sells the project's generation into the local organized wholesale market and then the buyer pays or receives the difference between the wholesale market revenue and the predetermined PPA price, in addition to the renewable energy credits.

4 The EIM initially launched with real-time trading and has been moving toward adding a day-ahead market as well. The EIM is not a full RTO and operates with a different governance structure.

5 The CLEAN Future Act is draft federal legislation and has not yet been introduced in Congress. There is no bill number, and the House Committee on Energy and Commerce is still requesting feedback and recommendations to refine the act.

6 When electricity is traded across areas with differing carbon policies, parties may import power or sell power in ways that distort the intended carbon reductions.

7 PJMCCC, for example, used both an organizational management expert and a subject matter expert to launch the coalition. It develops its strategy through committee work that considers the goals of the coalition, recent developments in the PJM market, and an understanding of what issues other stakeholders are engaging on and how.
8 We generally refer to the U.S. electricity system as a singular "grid," but the country actually has three grids: the Eastern Interconnection, the Western Interconnection, and the Texas Interconnection. Because Texas has its own interconnection, it is exempt from FERC's regulation of interstate power trading.

9 Nonintervenors who also want email notices on public information can use FERC's eSubscription service to receive updates, although not to the same extent as formal intervenors.

10 There have been exceptions where proposals have moved forward in PJM without stakeholder approval, including a PJM 2019 Reserve Planning Proposal (Bade 2019).

11 In SPP, RSC voting is considered "advisory."

12 For transmission-related issues, 205 rights belong to the owner of the transmission assets.

13 At the time of this paper's release, no PJMCCC members are currently in the Dual Members Tier, although some have plans to seek PJM membership.

14 Equity benefits stem from the ability of storage resources to replace peak plant capacity, which is known to be highly polluting and often situated close to vulnerable communities. Please see further detail in the policy statement: https://files.wri.org/s3fs-public/uploads/pjmcccstorage-policy-statement.pdf.

15 After this analysis concluded, FERC issued an order expanding the MOPR beyond PJM's proposal. It has ruled on all requests for rehearing and clarification.

16 The ISO portion of ISO-NE is a legacy acronym as the organization is technically a regional transmission organization. 
ACCC (American Cities Climate Challenge). 2020. "Local Government Renewables Action Tracker." https://cityrenewables.org/transaction-tracker/.

AEE (Advanced Energy Economy). 2020. "House CLEAN Future Act Provisions Expanding Competition and Consumer Access to Advanced Energy Will Lower Costs on the Path to $100 \%$ Clean." Wholesale Electricity Market Policy Briefs, July. https://info.aee.net/hubfs/Clean\%20Future\%20Act\%20brief\%20 (07-16-20).pdf.

AEE. 2021. "Organized Wholesale Markets and Corporate Advanced Energy Procurement." January. https://info.aee.net/aebg-organized-wholesalemarkets-and-corporate-advanced-energy-procurement.

Aggarwal, S., and M. O'Boyle. 2020. "Rewiring the U.S. for Economic Recovery." Energy Innovation, June. https://energyinnovation.org/ wp-content/uploads/2020/06/90-Clean-By-2035-Policy-Memo. pdf?__hstc=\&_hssc=\&hsCtaTracking=3976190d-7d4d-4022-ae726009387f5321\%7Cc2cda486-fe34-4f70-a251-a84294elea0d.

America's Pledge. 2020. "We Are Still In to Deliver on America's Pledge: A Retrospective." September. https://www.americaspledgeonclimate.com/ we-are-still-in-to-deliver-americas-pledge/.

Anders, D., and J. Fabiano 2019. "PJM Stakeholder Process Training." PJM, general presentation. November 6. Title: PJM Initiation of New Issues.

Bade, G. 2019. "PJM to Ask FERC to Invalidate Its Energy Market Rules after Stakeholder Impasse." Utility Dive, February 15. https://www.utilitydive. com/news/pjm-to-ask-ferc-to-invalidate-its-energy-market-rules-afterstakeholder-imp/548585/.

Ballentine, M. 2020. "Competition Can Unlock the US Clean Energy Economy." GreenBiz, January 5. https://www.greenbiz.com/article/competition-canunlock-us-clean-energy-economy.

CapX2020. 2020. CapX2050: Transmission Vision Report. March.

Caspary, J., M. Goggin, R. Gramlich, and J. Schneider. 2021. "Planning for the Future: FERC's Opportunity to Spur More Cost-Effective Transmission." Americans for a Clean Energy Grid, January.

Cavell, C. 2017. "Move to MISO Delivering Benefits." Entergy blog, May 15. https://www.entergynewsroom.com/news/move-miso-deliveringbenefits-1981/.

CGA (Clean Grid Alliance). 2019. "Clarion Call! Success Has Brought Us to the Limits of the Current Transmission System." Blog, November 12. https:// cleangridalliance.org/blog/118/clarion-call-success-has-brought-us-to-thelimits-of-the-current-transmission-system.

Chen, J. 2020. "Evaluating Options for Enhancing Wholesale Competition and Implications for the Southern United States." Duke University Nicholas Institute, March. https://nicholasinstitute.duke.edu/sites/default/files/publications/ Evaluating\%200ptions\%20for\%20Enhancing-Wholesale-Competition-andImplications-for-the-Southeastern-United-States-Final_0.pdf.
Dennis, J., S. Kelly, R. Nordhaus, and D. Smith. 2016. "Federal/State Jurisdictional Split: Implications for Emerging Electricity Technologies." Energy Analysis and Environmental Impacts Division, Lawrence Berkeley National Laboratory, December. https://www.energy.gov/sites/ prod/files/2017/01/f34/Federal\%20State\%20Jurisdictional\%20Split-Implications\%20for\%20Emerging\%20Electricity\%20Technologies.pdf.

Eto, J. 2016. "Planning Electric Transmission Lines: A Review of Recent Regional Transmission Plans." Energy Analysis and Environmental Impacts Division, Lawrence Berkeley National Laboratory, September.

FERC (Federal Energy Regulatory Commission). 2019. Final Report of Settlement Judge under ER18-2068. Issued December 2. https://elibrary.ferc. gov/eLibrary/filelist?document_id=14818049\&optimized=false.

FERC. 2020a. "FERC Proposes Policy Statement on State-Determined Carbon Pricing in Wholesale Markets." News, October 15. https://www.ferc.gov/ news-events/news/ferc-proposes-policy-statement-state-determinedcarbon-pricing-wholesale-markets.

FERC. 2020b. "Order on Compliance re Southwest Power Pool, Inc. under ER19-2522." Issued July 16. https://elibrary.ferc.gov/eLibrary/ filelist?document_id=14877305\&optimized=false.

FERC. 2020c. "Major Orders \& Regulations." https://www.ferc.gov/ enforcement-legal/legal/major-orders-regulations.

FERC. 2020d. "Off-the-Record Communications." https://www.ferc.gov/ enforcement-legal/legal/major-orders-regulatons/record-communications (accessed February 1).

FERC. 2021. "RTOs and ISOs." https://www.ferc.gov/industries-data/electric/ power-sales-and-markets/rtos-and-isos (accessed February 17).

Gardner, J. 2019. "RTO Stakeholder Processes: Principles and Best Practices." Western Resource Advocates, presentation to Regional Issues Forum, Albuquerque, NM, March 11.

Goggin, M., and R. Gramlich. 2020. "A Moving Target: An Update on the Consumer Impacts of FERC Interference with State Policies in the PJM Region." May. https://gridprogress.files.wordpress.com/2020/05/a-movingtarget-paper.pdf.

Goggin, M., et al. 2018. "Customer Focused and Clean: Power Markets for the Future." Prepared for the Wind Solar Alliance, November. https:// windsolaralliance.org/wp-content/uploads/2018/11/WSA_Market_Reform_ report_online.pdf.

Gonçalves, T., and Y. Liu. 2020. "How US Cities and Counties Are Getting Renewable Energy." World Resources Institute (blog), June 24. https://www. wri.org/blog/2020/06/renewable-energy-procurement-cities-counties.

James, M., and K.B. Jones. 2017. "Finding Efficiencies: Updating RT0 Stakeholder Governance to Meet Emerging Challenges." Utility Dive, December 15. https://www.utilitydive.com/news/finding-efficienciesupdating-rto-stakeholder-governance-to-meet-emerging/513085/. 
James, M., K.B. Jones, A.H. Krick, and R.R. Greane. 2017. "How the RTO Stakeholder Process Affects Market Efficiency." R Street Policy Study, October. http://www.ourenergypolicy.org/wp-content/uploads/2017/10/112.pdf.

Konidena, R. 2020. "To Clear the Backlog of Network Upgrades, We Need Steel in the Ground." Renewable Energy World, September 11. https:// www.renewableenergyworld.com/solar/to-clear-the-backlog-of-networkupgrades-we-need-steel-in-the-ground/.

Lombardi, S. 2019. "Integrating Markets and Public Policy (IMAPP): Overview of New England's 2016-17 IMAPP Process." Presented to the PJM Carbon Pricing Senior Task Force, October 24, https://www.pjm.com/-/media/ committees-groups/task-forces/cpstf/20191024/20191024-item-03-newengland-stakeholder-process-imapp.ashx.

Marcacci, S. 2019. "U.S. Electricity Markets Aren't Designed to Handle 100\% Clean Energy: Here's How to Fix That." Forbes, July 1. https://www. forbes.com/sites/energyinnovation/2019/07/01/u-s-electricity-marketsarent-designed-to-handle-100-clean-energy-heres-two-ways-to-fixthat/\#34711596e4ba.

Market Analysis and Forecasting. 2020. Western EIM Benefits Report. Prepared for California ISO, October 29. https://www.westerneim.com/ Documents/ISO-EIM-Benefits-Report-Q3-2020.pdf.

McCabe, A., D. Svanda, and B.A. Kane. 2019. "Making Markets Work for PJM States: State Engagement Possibilities with PJM." Organization of PJM States, October. https://opsi.us/wp-content/uploads/2019/10/Making-Markets-Workfor-PJM-States-10-14-19-1.pdf.

NESCOE (New England State Committee on Electricity). 2020. "New England States' Vision for a Clean, Affordable, and Reliable 21st Century Regional Electric Grid." October 16. http://nescoe.com/resource-center/vision-stmtoct2020/.

OPSI (Organization of PJM States Inc.), 2021. "Letter Regarding the Future of Resource Adequacy." To PJM Board of Managers, January 8. https://www. pjm.com/-/media/about-pjm/who-we-are/public-disclosures/20210114-opsiletter-re-the-future-resource-adequacy.ashx-.

Peeler, N. 2020. "New Southeast Energy Exchange Adds Value." Duke Energy News Center, December 11. https://news,duke-energy.com/our-perspective/ new-southeast-energy-exchange-adds-value\#: :text=SEEM\%20is\%20a\%20 15\%2Dminute,across\%20a\%20wide\%20geographic\%20area.\&text=The\%20 exchange\%20is\%20an\%20 extension\%20of\%20the\%20 existing\%20 bi\%2Dlateral\%20market.
Pfeifenberger, J. 2019. "Improving Transmission Planning: Benefits, Risks, and Cost Allocation." Midwestern Governors Association \& Organization of MISO States, November 6.

PJM. 2019. "PJM Cities Coalition Letter Regarding Leadership Transition." To PJM Board of Managers, July 24. https://www.pjm.com/-/media/about-pjm/ who-we-are/public-disclosures/20190726-pjm-cities-coalition-letterregarding-leadership-transition-at-pjm.ashx.

PJM. n.d. "Committees \& Groups." https://www.pjm.com/committees-andgroups (accessed February 5, 2020).

REBA (Renewable Energy Buyers Alliance). 2020. "Renewable Energy Buyer Organized Wholesale Market Design Principles." Washington, DC. https:// reba-institute.org/research/.

Sergici, S. 2019. "The Status of Restructuring: Wholesale and Retail Markets." Presented to National Conference of State Legislatures, June 26.

Simeone, C. 2017. "PJM Governance: Can Reforms Improve Outcomes?" Kleinman Center for Energy Policy, May 19.

St. John, J. 2020. "Southeastern Utilities Launch Plan for Regional Energy-Trading Market, Greentech Media, December 14, https://www. greentechmedia.com/articles/read/southeastern-utilities-launch-plan-forregional-energy-trading-market.

Sustainable FERC. 2020. "NRDC Sues FERC over Orders That Threaten NY Clean Energy." Sustainable FERC Project (blog), June 30. https:// sustainableferc.org/nrdc-sues-ferc-over-orders-that-threaten-ny-cleanenergy/.

Walton, R. 2020a. "FERC Rejection of NYISO Renewables Plan Could Prompt State-Managed Capacity Market, Advocates Say." Utility Dive, September 10. https://www.utilitydive.com/news/ferc-rejection-of-nyiso-renewables-plancould-prompt-state-managed-capacity/584948/.

Walton, R. 2020b. "New England States Call for Changes to Wholesale Markets, Transmission Planning and Grid Governance." Utility Dive, October 19. https://www.utilitydive.com/news/new-england-states-call-for-changesto-wholesale-markets-transmission-plan/587269/.

Wind Solar Alliance. 2018. "Corporate Renewable Procurement and Transmission Planning: Communicating Demand to RTOs Necessary to Ensure Future Procurement Options." October. https://windsolaralliance.org/ wp-content/uploads/2018/10/Corporates-Renewable-Procurement-andTransmission-Report-FINAL.pdf. 
ACKNOWLEDGMENTS

We are pleased to acknowledge our institutional strategic partners that provide core funding to WRI: the Netherlands Ministry of Foreign Affairs, Royal Danish Ministry of Foreign Affairs, and Swedish International Development Cooperation Agency.

The authors thank Lori Bird for the significant role she played as a project manager for both engagements with the PJM Cities and Communities Coalition (PJMCCC) as well as management of the research and writing of this report. We also appreciate research support from Jackson Drury, who developed early drafts during his time as a WRI intern. Norma Hutchinson, William Jungblut, and Priyanka Roche provided both support through their work with PJMCCC and additional research for this paper. Finally, this paper would not have been possible without PJMCCC and its leadership as the first city coalition organized specifically to address issues at the wholesale market level. The cities involved in various levels of engagement during the formalization of the group include Philadelphia, PA; Chicago, IL; Cleveland, $\mathrm{OH}$; Newark, NJ; Pittsburgh, PA; Washington, DC; Alexandria, VA; Baltimore, MD; Lancaster, PA; Cincinnati, OH; Richmond, VA; Roanoke, VA; Fairfax, VA; Falls Church, VA; Charlottesville, VA; Takoma Park, MD; Rockville, MD; Plano, TX; Columbus, OH; Norfolk, VA; and Evanston, IL.

The content of this paper is the sole responsibility of the authors. However, the authors would like to thank the following individuals for their insightful comments and critical reviews. We thank our expert advisory council, which included Steve Abbott at Rocky Mountain Institute; Adam Agalloco from the International Finance Corporation; Elise Caplan, formerly with the American Public Power Association; Jennie Chen, formerly at Duke University's Nicholas Institute for Environmental Policy Solutions and now founder of ReGrid; Lara Cottingham at the City of Houston; Jon Crow and Rich Freeh at the Urban Sustainability Directors Network; Maribeth DeLorenzo at the City of Washington, DC; Bill Eger at the City of Alexandria; Amy Fredregill, formerly at the Sustainable Growth Coalition and now at WSB; Zachary Greene, formerly at the Natural Resources Defense Council and now at WRI; Ellen Katz at the Cambridge (MA) Department of Public Works; Caitlin Marquis and Jeff Dennis at Advanced Energy Economy; Ann McCabe and David Farnsworth at the Regulatory Assistance Project; Elizabeth Noll at Coefficient Group; Matthew Prorok and Brian Ross from Great Plains Institute; Stefen Samarripas at the American Council for an Energy-Efficient Economy; and Amanda Warwood, formerly at the City of Philadelphia and now at ANDRIS Consulting.
This report was made possible thanks to the support of the U.S. Department of Energy through the Office of Energy Efficiency and Renewable Energy under the Solar Energy Technologies Office Award Number DE-EE0009003.

This report was prepared as an account of work sponsored by an agency of the U.S. Government. Neither the U.S. Government nor any agency thereof, nor any of their employees, makes any warranty, express or implied, or assumes any legal liability or responsibility for the accuracy, completeness, or usefulness of any information, apparatus, product, or process disclosed, or represents that its use would not infringe privately owned rights.

Reference herein to any specific commercial product, process, or service by trade name, trademark, manufacturer, or otherwise does not necessarily constitute or imply its endorsement, recommendation, or favoring by the U.S. Government or any agency thereof. The views and opinions of authors expressed herein do not necessarily state or reflect those of the U.S. Government or any agency thereof.

The authors thank the following individuals for their insightful comments and critical reviews: Juan Carlos Altamirano, Shannon Hilsey, Lacey Shaver, and Debbie Weyl.

The authors also thank Laura Malaguzzi Valeri and Emilia Suarez of WRI's Research, Data, and Innovation office for their insights, Emily Matthews and Alex Martin for copyediting, Romain Warnault for coordinating the production process, and Shannon Collins for design and layout. 
ABOUT THE AUTHORS

Heidi Bishop Ratz is a Manager, U.S. Electricity Markets, working across the Global Energy and Climate Programs at World Resources Institute. She provides project management, partner engagement, and research to drive the transition to a low-carbon economy in the United States. This involves research and analysis to support WRI's existing and emerging U.S. energy initiatives related to deep decarbonization, electricity market design, innovative utility regulatory policy, and/or promotion of zero- and lowcarbon energy, demand response, energy storage, and energy efficiency.

Contact: Heidi.ratz@wri.org

Priyanka Roche is a Research Analyst, U.S. Energy Program, at World Resources Institute and works on multiple projects that focus on a lowcarbon transition in the U.S. power sector. She provides research support on state regulatory policies, federal programs, and electricity market design to initiatives that drive clean energy adoption.

Contact: Priyanka.Roche@wri.org

Norma Hutchinson is a Research Analyst within the Global Energy Program at World Resources Institute. In this role, she supports research and analysis on deep decarbonization, innovative utility regulatory policy, and transportation electrification both in the United States and internationally.

Contact: Norma.Hutchinson@wri.org
ABOUT WRI

World Resources Institute is a global research organization that turns big ideas into action at the nexus of environment, economic opportunity, and human well-being.

\section{Our Challenge}

Natural resources are at the foundation of economic opportunity and human well-being. But today, we are depleting Earth's resources at rates that are not sustainable, endangering economies and people's lives. People depend on clean water, fertile land, healthy forests, and a stable climate. Livable cities and clean energy are essential for a sustainable planet. We must address these urgent, global challenges this decade.

\section{Our Vision}

We envision an equitable and prosperous planet driven by the wise management of natural resources. We aspire to create a world where the actions of government, business, and communities combine to eliminate poverty and sustain the natural environment for all people.

\section{Our Approach}

COUNT IT

We start with data. We conduct independent research and draw on the latest technology to develop new insights and recommendations. Our rigorous analysis identifies risks, unveils opportunities, and informs smart strategies. We focus our efforts on influential and emerging economies where the future of sustainability will be determined.

\section{CHANGE IT}

We use our research to influence government policies, business strategies, and civil society action. We test projects with communities, companies, and government agencies to build a strong evidence base. Then, we work with partners to deliver change on the ground that alleviates poverty and strengthens society. We hold ourselves accountable to ensure our outcomes will be bold and enduring.

\section{SCALE IT}

We don't think small. Once tested, we work with partners to adopt and expand our efforts regionally and globally. We engage with decision-makers to carry out our ideas and elevate our impact. We measure success through government and business actions that improve people's lives and sustain a healthy environment. 